\title{
PHYSICAL AND CHEMICAL CHARACTERIZATION OF SYNTHETIC CALCINED SLUDGE
}

ROBERT V. SLATES

W. CLANTON MOSLEY, JR.

BURTON TIFFANY

JOHN A. STONE

\section{TIS FILE RECORD COPY}

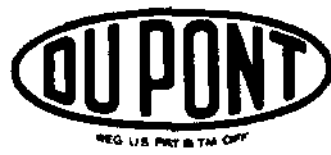

E. I. du Pont de Nemours \& Co. Savannah River Laboratory Aiken, SC 29808 


\section{DISCLAIMER}

This report was prepared by E. 1. du Pont de Nemours and Company (Du Pont) for the United States Department of Energy under Contract DE-ACO9-76SR00001 and is an account of work performed under that Contract. Neither the United States, the United States Department of Energy nor Du Pont, nor any of their employees, makes any warranty, express or implied, or assumes any legal liability or responsibility for the accuracy, completeness, or usefulness of any information, apparatus, product, or process disclosed herein, or represents that its use will not infringe privately owned rights. Reference herein to any specific commerical product, process, or service by trade name, mark, manufacturer, or otherwise does not necessarily constitute or imply endorsement, recommendation, or favoring of same by Du Pont or by the United States Government or any agency thereof. The views and opinions of authors expressed herein do not necessarily state or reflect those of the United States Government or any agency thereof.

Printed in the Unted States of America
Available from
National Technical Information Service
U. S. Department of Commerce
5285 Port Aoyal Aoad
Springtiotd. Virginia 22161
Price: Printed Copy A05; Microfiche A01




\section{PHYSICAL AND CHEMICAL CHARACTERIZATION OF SYNTHETIC CALCINED SLUDGE}

ROBERT V. SLATES, CONTRIBUTOR AND EDITOR

W. CLANTON MOSLEY, JR., CONTRIBUTOR

BURTON TIFFANY, CONTRIBUTOR

JOHN A. STONE, CONTRIBUTOR

Approved by:

M. L. Hyder

Analytical Chemistry

Published: March 1982

\section{E. I. du Pont de Nemours \& Co. Savannah River Plant and Laboratory Aiken, SC 29808}


Calcined synthetic sludge was chemically characterized in support of engineering studies to design a processing plant to solidify highly radioactive waste at the Savannah River Plant. An analytical technique is described which provides quantitative data by mass spectrometric analysis of gases evolved during thermogravimetric analysis without measurements of gas flow rates or mass spectrometer sensitivities. Scanning electron microprobe analysis, Mossbauer spectroscopy, and several other common analytical methods were also used.

Calcined sludge consists primarily of amorphous particles of hydrous oxides with iron, manganese, nickel, and calcium distributed fairly uniformly throughout the powder. Iron, manganese, nickel, and calcium exist in forms that are highly insoluble in water, but aluminum, sulfate, nitrate, and sodium exhibit relative water solubilities that increase in the given order from $60 \%$ to $94 \%$. Evolved gas analys is in a helium atmosphere showed that calcined sludge is completely dehydrated by heating to $400^{\circ} \mathrm{C}$, carbon dioxide is evolved between 100 to $700^{\circ} \mathrm{C}$ with maximum evolution at $500^{\circ} \mathrm{C}$, and oxygen is evolved between 400 and $1000^{\circ} \mathrm{C}$. Evolved gas analyses are also reported for uncalcined sludge. A spine1-type oxide similar to $\mathrm{NiFe}_{2} \mathrm{O}_{4}$ was detected by $x$-ray diffraction analys is at very low-1evel in calcined sludge. 
INTRODUCTION 9

CHARACTERIZATION AND ANALYSES 10

Physical Characterization and X-ray Diffraction Analyses 10

Elemental, Ionic, and Spectral Analyses 13

Scanning Electron Microprobe Analyses 13

Thermal and Evolved Gas Analyses 21

Mossbauer Spectral Analyses 50

CONCLUSIONS 50

ACKNOWLEDGMENTS 53

REFERENCES 54

APPENDICES 55

Appendix $1 \quad 57$

Appendix $2 \quad 59$

Appendix $3 \quad 69$ 


\section{LIST OF TABLES}

1 The Quantity and Relative Water Solubility of Principal Elements and Ions in Calcine 14

2 Scanning Electron Microprobe Analysis of Compacted Calcine Pellet 17

3 Scanning Electron Microprobe Analyses of Calcine Particles Dispersed with No Pretreatment 19

4 Comparison of Microprobe Analyses and Chemical Analyses for Unwashed Calcine 19

5 Scanning Electron Microprobe Analyses of Calcine Particles Dispersed After Washing with Water 22

6 Experimental Data for Calcine Analysis Organized for Sensitivity Calculations 33

7 Evolved Gas Sensitivities for Calcine Analysis 34

8 Test of Evolved Gas Sensitivities for Calcine Analysis 35

9 Experimental Data for Sludge Analysis Organized for Sensitivity Calculations 46

10 Evolved Gas Sensitivities for Sludge Analysis 47

11 Test of Evolved Gas Sensitivities for Sludge Analysis 48 


\section{LIST OF FIGURES}

1 Photomicrographs of Calcine Particles 11

2 Particle Size Distributions for Calcine 12

3 Infrared Spectrum of Calcine 15

4 Comparison of Microprobe and Chemical Analyses for Unwashed Calcine 20

5A X-Ray Maps of Water-Washed Particle 6 for Manganese, Iron, and Nickel 23

5B X-Ray Maps of Water-Washed Particle 6 for Aluminum, Calcium, and Sodium 24

6 Thermogravimetric Analysis of Calcine 26

7 Evolved Gas Curve at Mass 18 for Calcine 27

8 Evolved Gas Curve at Mass 28 for Calcine 28

9 Evolved Gas Curve at Mass 30 for Calcine 29

10 Evolved Gas Curve at Mass 32 for Calcine 30

11 Evolved Gas Curve at Mass 44 for Calcine 31

12 Test of Evolved Gas Sensitivities for Calcine Analysis 36

13 Thermogravimetric Analysis of Sludge 38

14 Evolved Gas Curve at Mass 18 for Sludge 40

15 Evolved Gas Curve at Mass 28 for Sludge 41

16 Evolved Gas Curve at Mass 30 for Sludge 42

17 Evolved Gas Curve at Mass 32 for Sludge 43

18 Evolved Gas Curve at Mass 44 for Sludge 44

19 Test of Evolved Gas Sensitivities for Sludge Analysis 45

20 Differential Thermal Analysis of Calcine 51

21 Mossbauer Spectrum of Calcine at Room Temperature 52 
PHYSICAL AND CHEMICAL CHARACTERIZATION

OF SYNTHETIC CALCINED SLUDGE

\section{INTRODUCTION}

The Savannah River Laboratory (SRL) is preparing conceptual designs for a processing plant to convert approximately 20 million gallons ${ }^{1}$ of highly radioactive liquid waste to a solid form for safe long-term storage at an offsite federal repository. In the reference process, a slurry of the alkaline waste sludge will be spray-calcined, and the calcine powder will be fused with glass frit in a continuous glass melter. These melts of glass incorporating the radioactive calcine will be solidified in stainless steel cylinders ( $2-\mathrm{ft}$ diameter by $8-\mathrm{ft}$ long) which will be sealed by welding. Carbon steel secondary containers will be provided for shipment and storage.

Nonradioactive substitutes are routinely used to simulate radioactive waste for process development and related studies. Nonradioactive substitutes do not require shielding and containment but give valid experimental results because most of the chemical and physical properties of the waste are imparted by the nonradioactive components. Radioactive elements constitute, at most, a small fraction of the total waste. The calcine characterized in this study was a nonradioactive substitute prepared from a synthetic calciner feed slurry as described in Appendix 1.

Calcine was prepared by dehydration of the calciner feed slurry in the 21-inch-diameter spray calciner at Battelle Pacific Northwest Laboratories. The sludge studied by thermogravimetric and evolved gas analyses was obtained by vacuum filtration of the calciner feed slurry.

The goals of this work were (1) to characterize the calcine, (2) to provide a compositional basis for studies of the chemical reactions of calcine during and after fusion with glass, and (3) to evaluate analytical methods potentially applicable to the characterization of radioactive calcine. These goals were adequately met for preliminary engineering needs by a general characterization of the calcine. The scope of this work was therefore limited to analytical techniques readily available at SRL. On the basis of this general characterization, further work will be planned as necessary to meet specific requirements in the development of the conceptual designs for the waste solidification facility. 


\section{CHARACTERIZATION AND ANALYSES}

\section{Physical Characterization and X-Ray Diffraction Analyses}

Photomicrographs of the rust-colored powder are shown at different magnifications in Figure 1. The photomicrographs were made with a scanning electron microscope on a physically dispersed sample of calcine. The photomicrographs show that the calcine is composed of approximately spherical particles of nonuniform size which tend to form loose agglomerates.

The particle size distribution of calcine was determined with a Coulter Counter Model TA-II (Coulter Electronics, Inc.) by using Isoton $I I^{\oplus}$ (Coulter Diagnostics Division of Coulter Electronics, Inc.) electrolyte solution and a $70 \mu \mathrm{m}$ aperture. The calcine particle size distributions are shown in Figure 2. Although the $70 \mu \mathrm{m}$ aperture limited measurements to particles of less than $32 \mu \mathrm{m}$ diameter, the data show that the calcine particles range in diameter from about $3 \mu \mathrm{m}$ to at least $30 \mu \mathrm{m}$ with a mean particle diameter of about $15 \mu \mathrm{m}$.

$X$-ray diffraction analyses were run on calcine and on related materials. X-ray diffraction data showed that the calcine as received for analysis was primarily amorphous, but some crystalline phase was detected. The crystalline phase was identified as a spine1-type oxide similar to $\mathrm{Ni} \mathrm{Fe}_{2} \mathrm{O}_{4}$ with a cubic structure and a lattice constant of $8.33 \AA$. X-ray diffraction analysis was also run on calcine after heating to $1000^{\circ} \mathrm{C}$ in a helium atmosphere during thermogravimetric analysis. After heating to $1000^{\circ} \mathrm{C}$, three crystalline phases were identified. The major crystalline phase was a spinel-type oxide with cubic lattice constant of $8.443 \AA$. The two minor crystalline phases were $\mathrm{B}^{-\mathrm{Al}_{2} \mathrm{O}_{3}} \cdot 3_{2} \mathrm{O}$ (Bayerite) and $\mathrm{Na}_{2} \mathrm{CO}_{3} \cdot \mathrm{H}_{2} \mathrm{O}$. The calcine sample had apparently reabsorbed water and carbon dioxide during the three-week storage period between the thermogravimetric analysis and the $x$-ray diffraction analysis. For comparison with the calcine analysis, x-ray diffraction analysis was run on the sludge sample which had been heated to $1000^{\circ} \mathrm{C}$ in a helium atmosphere during thermogravimetric analysis. The major crystalline phase in sludge after heating to $1000^{\circ} \mathrm{C}$ was a spinel-type oxide with cubic lattice constant of 8.492A. An unidentified crystalline phase was present at the trace level in this sludge sample. X-ray diffraction analys is was also run on a crystalline residue that formed during the scanning electron microprobe studies of calcine. Water-soluble components were separated from water-insoluble components by washing the calcine with water. X-ray diffraction analysis of the crystalline residue which formed upon evaporation of the wash solution showed that the residue consisted of $\mathrm{B}_{-}-\mathrm{Al}_{2} \mathrm{O}_{3} \cdot 3 \mathrm{H}_{2} \mathrm{O}$ (Bayerite) and $\mathrm{Na}_{2} \mathrm{CO}_{3} \cdot \mathrm{NaHCO}_{3} \cdot 2 \mathrm{H}_{2} \mathrm{O}$ (sodium sesquicarbonate). 

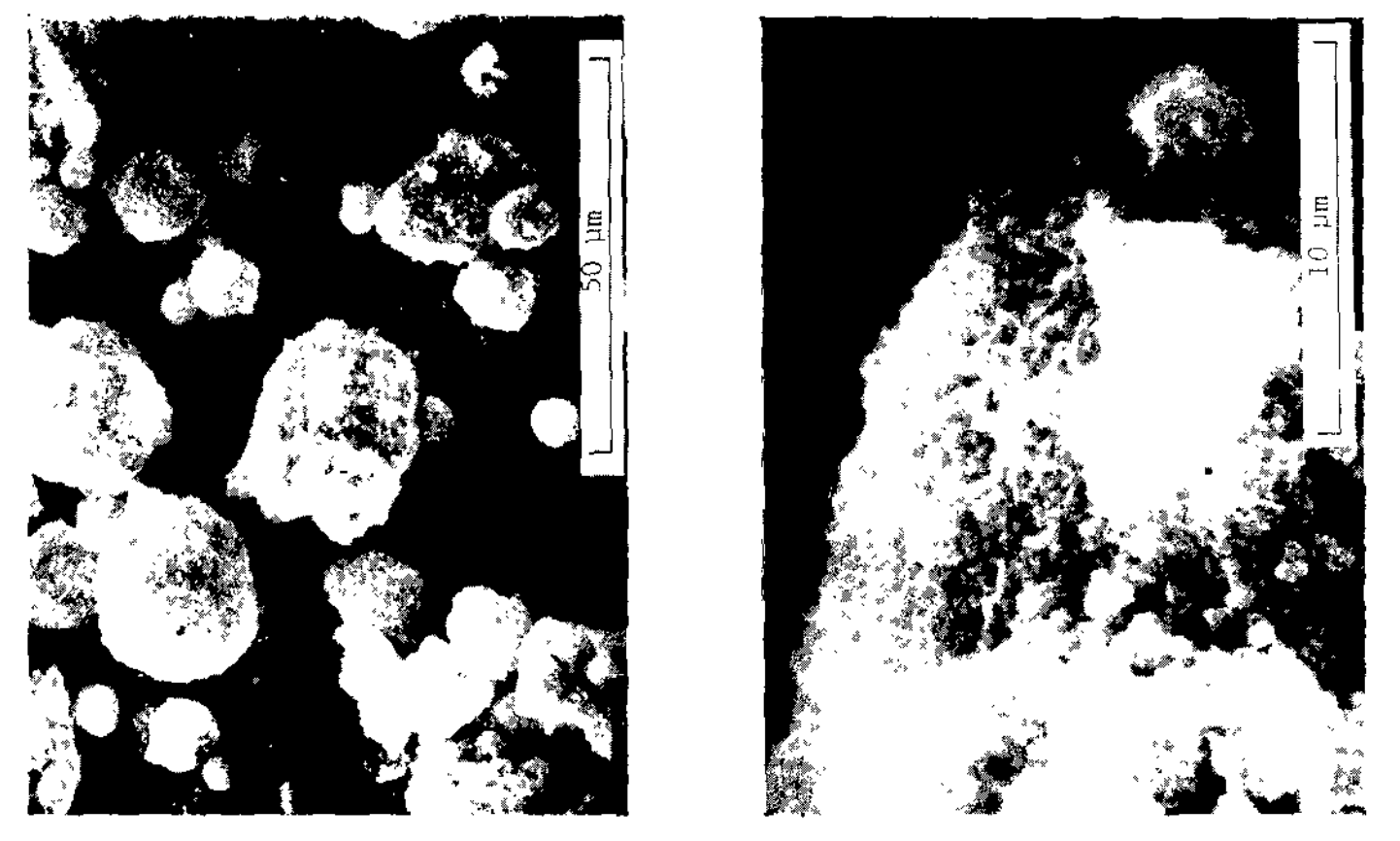

离
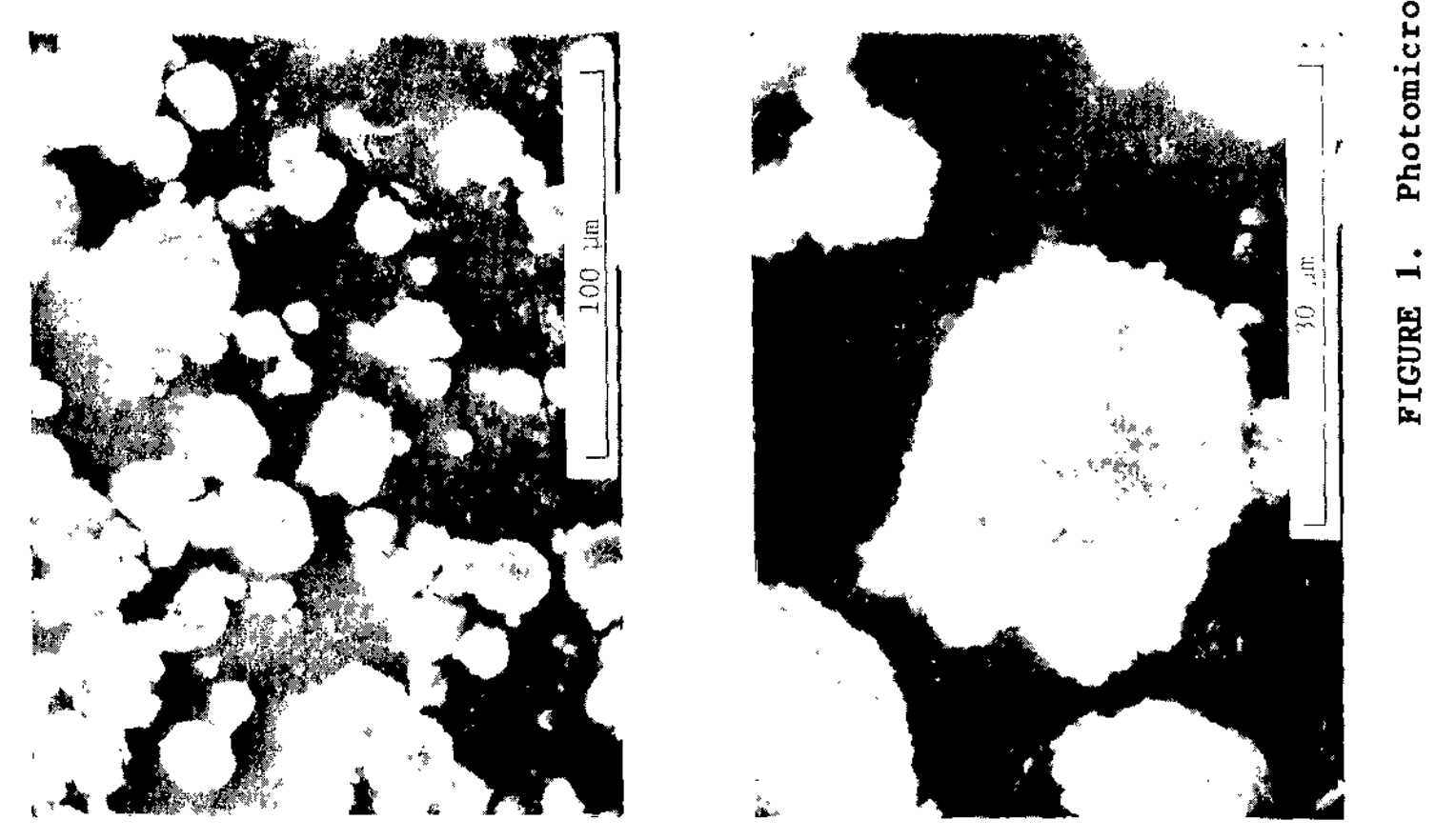


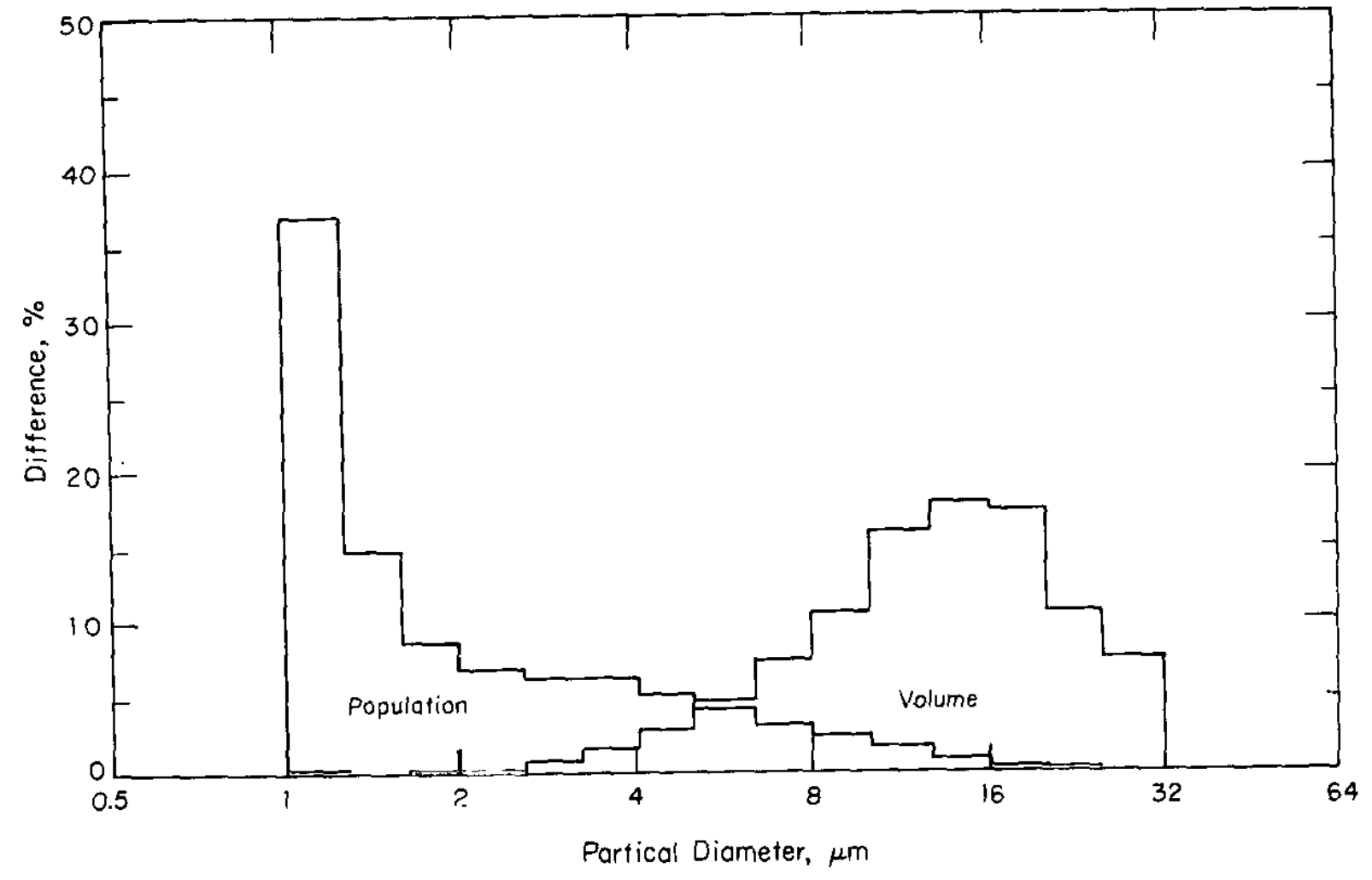

FIGURE 2. Particle Size Distributions for Calcine 
Elemental, Ionic, and Spectral Analyses

The principal elemental and ionic species in the calcine were known from the chemicals used to prepare the calciner feed slurry. The composition of the calcine, however, was not known quantitatively because a wash step in the calciner feed slurry preparation removed an undetermined quantity of soluble species and because chemical reactions and thermal decompositions during calcination may have altered the relative composition.

To quantify the principal elemental and ionic species in the calcine, chemical analyses were performed on calcine dissolved in $7.8 \mathrm{M} \mathrm{HCl}$. Similar analyses were performed to determine the watersoluble and water-insoluble fractions for each species. The quantity and relative water solubility of principal elemental and ionic species in calcine are given in Table 1 . The metal ions were determined by atomic absorption spectrometry; nitrate and sulfate were determined by ion chromatography. Nitrite was not determined in calcine because chemical analysis of the feed slurry before calcination showed that the nitrite content was only $2 \%$ of the nitrate content and because calcination at greater than $300^{\circ} \mathrm{C}$ was expected to further reduce the nitrite content significantly. Water-extractable carbonate was determined by acid titration to be $9.0 \%$ of the calcine and by total carbon analysis, using a Leco Total Carbon Analyzer (Laboratory Equipment Corporation), to be $5.2 \%$ of the calcine. The $5.2 \%$ carbonate value was calculated from the average of five precise determinations (Relative Standard Deviation $=5.7 \%$ ) by using different sample sizes and is considered more reliable than the result of the single acid titration.

The calcine was analyzed by spark source mass spectrometry to detect unexpected elements if present. No significant quantities of unexpected elements were detected.

The infrared spectrum of calcine prepared as a $\mathrm{KBr}$ pellet is shown in Figure 3. The presence of water in the calcine is indicated by the broad absorption peak at approximately $3500 \mathrm{~cm}^{-1}$. Although absorption peaks typical of inorganic carbonates are present in the spectrum at approximately $880 \mathrm{~cm}^{-1}$ and $1470 \mathrm{~cm}^{-1}$, the infrared spectrum provides 1 ittle information on the calcine composition.

\section{Scanning Electron Microprobe Analyses}

Scanning electron microprobe analyses were performed on calcine that had been pressed into a pellet, on individual calcine particles that had received no prior treatment, and on individual calcine particles that had been washed with water to remove soluble surface components. These results are presented separately in the following sections. 
TABLE 1

THE QUANTITY AND RELATIVE WATER SOLUBILITY OF PRINCIPAL ELEMENTS AND IONS IN CALCINE

\begin{tabular}{|c|c|c|}
\hline $\begin{array}{l}\text { Element } \\
\text { or Ion }\end{array}$ & $\begin{array}{l}\text { Total Wt } \% \\
\text { in Calcine }\end{array}$ & $\begin{array}{l}\text { Wt } \% \text { Solubie } \\
\text { in Water }\end{array}$ \\
\hline $\begin{array}{l}\mathrm{Fe} \\
\mathrm{Na} \\
\mathrm{Al} \\
\mathrm{Mn} \\
\mathrm{Ni} \\
\mathrm{Ca} \\
\text { Carbonate } \\
\text { Nitrate } \\
\text { Sulfate }\end{array}$ & $\begin{array}{c}23.5 \\
13.9 \\
8.4 \\
5.5 \\
3.2 \\
1.9 \\
5.2^{b} \\
1.2 \\
3.9\end{array}$ & $\begin{aligned} &< 5.2 \\
& 94 . \\
& 60 . \\
&< 0.1 \\
&< 3.7 \\
&< 3.1 \\
& b \\
& \\
& 88 . \\
& 73 .\end{aligned}$ \\
\hline
\end{tabular}

${ }^{a}$ Calcine samples were weighed for analysis as received with no prior drying. Percentages do not total $100 \%$ because oxide and water contents are not available.

${ }^{b}$ Carbonate was calculated from total carbon analysis. Acid titration suggests that carbonate in calcine is highly water soluble. 
Wavelength, $\mu$

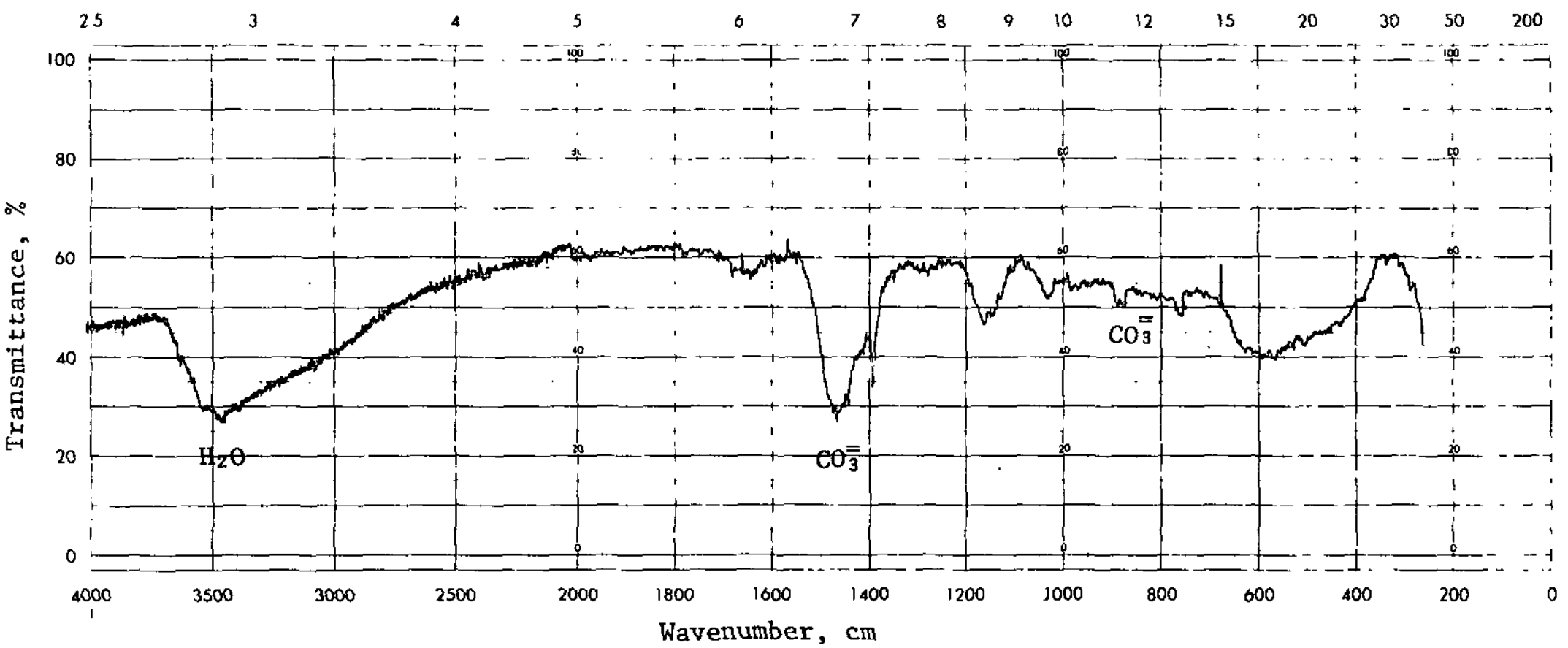

FIGURE 3. Infrared Spectrum of Calcine 


\section{Analysis of Compacted Calcine Pellet}

Calcine was compacted at a pressure of about $15,0001 \mathrm{bs} / \mathrm{in} .^{2}$ to form a small pellet suitable for analysis. Upon observation with the scanning electron microprobe, two distinct phases were apparent: compacted calcine particles and crystalline flakes. The scanning electron microprobe analyses of the compacted calcine and of the crystalline flakes which formed on the pellet surface are reported in Table 2 .

The wide-area analysis of the pellet surface gave results greatly different from the expected composition of Table 1 . The reported sodium content of $22 \%$ was greater than the expected bulk sodium content of $13.9 \%$ determined by atomic absorption spectrometry. Furthermore, the reported contents for iron, aluminum, manganese, nickel, and calcium (respectively $3.6 \%, 4.0 \%, 0.9 \%$, $0.4 \%$, and $0.2 \%$ ) were significantly smaller than the expected bulk values $(23.5 \%, 8.4 \%, 5.5 \%, 3.2 \%$, and $1.9 \%)$. Compared to the other metals, the high value for sodium in calcine was explained by the analytical data for one of the crystalline flakes. The microprobe analysis indicated that the crystalline flake was composed of sodium and oxygen with no other detectable elements exceeding $0.3 \%$. The presence of nitrogen, carbon, and hydrogen in the flake is uncertain; the instrument was not set up to determine nitrogen or carbon, and it is not applicable to hydrogen analysis. Consequently, the high value for sodium compared to those for the other metals in the wide-area analysis of the calcine pellet is accounted for because during the wide-area analysis, a large fraction of the raster time was spent analyzing crystalline flakes which contained a relatively high concentration of sodium. A relatively small fraction of the raster time was spent analyzing calcine particles.

Analyses of the compacted calcine particles were obtained relatively free of the effects of crystalline flakes by increasing the magnification and analyzing regions where flakes did not obscure the calcine particles. By making the visual display sensitive to one element at a time and rastering an area devoid of flakes, the spatial distribution and relative concentration of each element in the calcine could be visually observed. Small apparent variations in the elemental concentrations were noted for each element. Microprobe analyses were performed on four areas of the compacted particles: typical area, high-iron area, low- manganese area, and high-manganese area. These analyses are also reported in Table 2. The significance of these four analyses will be discussed below with the analytical results of individual calcine particles analyzed with no pretreatment. 
TABLE 2

SCANNING ELECTRON MICROPROBE ANALYSIS OF COMPACTEO CALCINE PELLET

Composition in Weight Percent
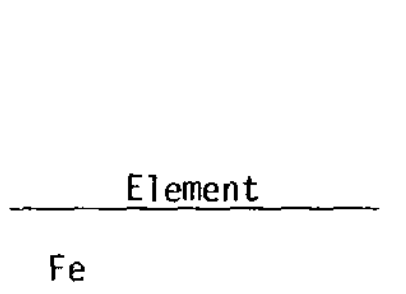

$\mathrm{Na}$

A1

Mn

$\mathrm{Ni}$

$\mathrm{Ca}$

0

S

Analysis

Conditions

\section{Magnification}

Raster Time (sec)

Crystalline
Flake

0.3

42.

0.03

0.1

0.07

0.05

14.

0.03

$5 K$

0.2
500

0.2

\section{Compacted Calcine Particles}

Wide-Area

Flakes \& Calcine

3.6

22.

4.0

0.9

0.4

0.2

17.

0.6

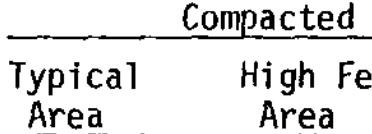

Low Mn
Area

High Mn

18

20.

18.

22.

17.

Area

9.4

8.8

22.

16.

5.1

5.4

11.

15.

2.0

2.4

8.8

1.1

2.2

1.9

12.

18.

1.6

0.4

1.7

18.

17.

16.

0.7

1.2

1.1

1.2

15.

1.0

$\begin{array}{llcc}2 K & 5 K & 10 K & 10 K \\ 0.2 & 0.2 & 0.2 & 0.2\end{array}$




\section{Analysis of Dispersed Particles, No Pretreatment}

Calcine particles were prepared for microprobe analys is with no pretreatment by physically dispersing them on a carbon disk and by attaching them to the disk with a few drops of Lexan ${ }^{\otimes}$ (General Electric Co.) polycarbonate resin dissolved at very low concentra$t$ ion in $60 \%$ dichloromethane and $40 \%$ dichloroethane. Upon evaporation of the solvent, a very thin polycarbonate film bonded the calcine particles to the carbon disk. A very thin layer of carbon was then deposited on the particles by evaporation to prevent electrical charging. Scanning electron microprobe analyses of four individual unwashed calcine particles are reported in Table 3 . Average compositions for unwashed calcine are compared in Table 4 and in Figure 4 with the bulk composition determined by chemical analyses.

The microprobe analyses of compacted calcine and of dispersed calcine are significant because they show that each individual calcine particle contains the same elements and has approximately the same composition as all other particles. Although the apparent variations in concentration from one particle to another are probably real, these data show no indication of elemental separation to form particles of distinctly different composition.

The accuracy of the scanning electron microprobe analyses is indicated by the data of Table 4 which is shown graphically in Figure 4. In this figure, the average composition of calcine determined by microprobe analysis is graphed against the bulk chemical composition determined by chemical analysis. If the microprobe analyses agreed exactly with the chemical analyses, all of the data points would lie on the line of unit slope through the origin. The experimental data points all lie close to the line of unit slope in spite of the large range of values for iron, sodium, and manganese, and indicate that the averaged microprobe analyses are quite accurate. The reliability of the microprobe oxygen determination can be inferred even though the oxygen content was not determined by bulk chemical analysis. The oxygen content of the calcine can be estimated to be about $42 \%$ by subtracting the known constituents from $100 \%$. The average oxygen content of $12.2 \%$ determined by microprobe analys is must therefore be grossly underestimated. Although little confidence should be placed in the microprobe oxygen analyses of calcine, the microprobe analyses for all other principal elements in calcine appear to be quite reliable.

\section{Analysis of Dispersed Particles After Hater Hssh}

Calcine particles were thoroughly washed with water to remove soluble surface components and were prepared for microprobe analysis by dispersing them on a carbon disk as previously described. 
TABLE 3

SCANNING ELECTRON MICROPROBE ANALYSES OF CALCINE PART ICLES DISPERSED WITH NO PRETREATMENT

\begin{tabular}{|c|c|c|c|c|}
\hline \multirow[b]{2}{*}{ Element } & \multicolumn{4}{|c|}{ Composition in Weight Percent } \\
\hline & $\begin{array}{c}\text { Particle } \\
1 \\
\end{array}$ & $\begin{array}{c}\text { Particle } \\
2 \\
\end{array}$ & $\begin{array}{c}\text { Particle } \\
3 \\
\end{array}$ & $\begin{array}{c}\text { Particle } \\
4 \\
\end{array}$ \\
\hline $\mathrm{Fe}$ & 24. & 31. & 26. & 22. \\
\hline $\mathrm{Na}$ & 5.9 & 13. & 12. & 17 . \\
\hline Al & 9.1 & 13. & 9.5 & 12. \\
\hline$M n$ & 14. & 5.7 & 9.0 & 3.5 \\
\hline $\mathrm{Ni}$ & 2.7 & 3.4 & 2.7 & 2.5 \\
\hline $\mathrm{Ca}$ & 1.3 & 1.9 & 1.3 & 3.8 \\
\hline 0 & 3.6 & 14. & 7.8 & 5.6 \\
\hline$S$ & 0.3 & 0.9 & 0.4 & 0.8 \\
\hline \multicolumn{5}{|l|}{ Analys is } \\
\hline \multicolumn{5}{|l|}{ Conditions } \\
\hline Magnification & $10 \mathrm{~K}$ & $10 \mathrm{~K}$ & $10 K$ & $10 \mathrm{~K}$ \\
\hline Raster Time (sec) & 0.2 & 0.2 & 0.2 & 0.2 \\
\hline
\end{tabular}

TABLE 4

\begin{tabular}{|c|c|c|c|c|}
\hline Element & $\begin{array}{l}\text { Average } \\
\text { of } 4 \\
\text { Pellet } \\
\text { Analyses }\end{array}$ & $\begin{array}{l}\text { Average } \\
\text { of } 4 \\
\text { Particle } \\
\text { Analyses } \\
\end{array}$ & $\begin{array}{l}\text { Average } \\
\text { of All } 8 \\
\text { Analyses }\end{array}$ & $\begin{array}{l}\text { Bulk } \\
\text { Calcine } \\
\text { Composition }\end{array}$ \\
\hline $\mathrm{Fe}$ & 17.8 & 25.8 & 21.8 & 23.5 \\
\hline $\mathrm{Na}$ & 19.2 & 12.0 & 15.6 & 13.9 \\
\hline $\mathrm{Al}$ & 9.5 & 10.9 & 10.2 & 8.4 \\
\hline $\mathrm{Mn}$ & 6.2 & 8.0 & 7.1 & 5.5 \\
\hline $\mathrm{Ni}$ & 2.0 & 2.8 & 2.4 & 3.2 \\
\hline $\mathrm{Ca}$ & 1.0 & 2.1 & 1.6 & 1.9 \\
\hline 0 & 16.5 & 7.8 & 12.2 & $\cdots$ \\
\hline$S$ & 1.1 & 0.6 & 0.8 & 1.3 \\
\hline $\begin{array}{l}\text { From } \\
\text { Table }\end{array}$ & 2 & 3 & $2 \& 3$ & 1 \\
\hline
\end{tabular}




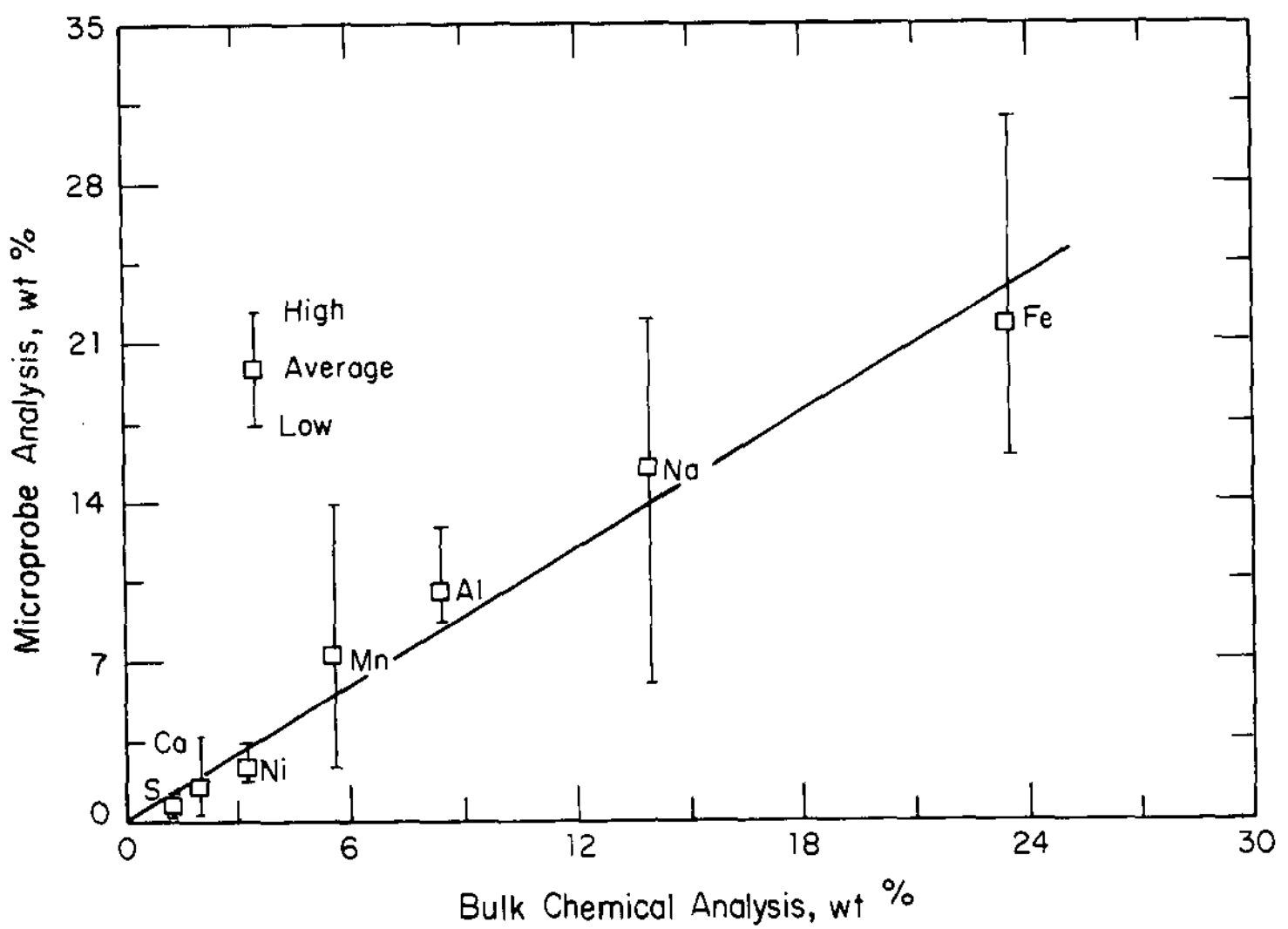

FIGURE 4. Comparison of Microprobe and Chemical Analyses for Unwashed Calcine 
Microprobe analyses for six large particles and for two small particles are reported in Table 5 .

Comparison of the composition data of Tables 3 and 5 shows that the water wash removed part of the aluminum and essentially all of the sodium and sulfate. These data support the conclusion that each individual particle contains the same elements at approximately the same concentration as all other particles, and shows additionally that small particles are not significantly different from large particles. The elemental composition appears to vary randomly from particle to particle, but the variation appears limited to a certain composition range. For example, the iron content of water-washed calcine appears to vary around a mean of about $40 \%$, aluminum appears to vary around a mean of about $6 \%$, etc.

Composition variations within a single calcine particle were investigated by analyzing Particle 6 . X-ray maps showing the elemental distributions for manganese, iron, nickel, aluminum, calcium, and sodium in the indicated analysis area are presented in Figures $5 \mathrm{~A}$ and $5 \mathrm{~B}$. The concentration of each indicated element is proportional to the number of white dots in the $x$-ray map. These $x$-ray maps show that each of the analyzed elements is quite uniformly distributed over the analyzed area of the particle. No concentration variations are apparent for sodium, aluminum, and calcium; however, this particle had been prewashed with water so that only residual sodium and aluminum would be detected. Minor concentration variations are indicated for iron, nickel, and manganese. Careful inspection of the x-ray maps for iron, nickel, and manganese shows that in the region of higher manganese concentration, the concentrations of iron and nickel are slightly depressed.

\section{Thermal and Evolved Gas Analyses}

Gases evolved during thermogravimetric analysis (TGA) of calcine and of sludge from the calciner feed slurry were analyzed by mass spectrometry. In addition, differential thermal analysis (DTA) was run on the calcine sample. Details of these analyses are discussed below.

\section{Instrumentation and Experimental Procedure}

A Du Pont Model 900 differential thermal analyzer, a Du Pont Model 950 thermogravimetric analyzer, and a Finnigan Model 1015-C quadrupole mass spectrometer were used for the thermal and evolved gas analyses. Gases evolved during the thermogravimetric analyses were sampled by a short nickle capillary tube inserted into the 
SCANNING ELECTRON MICROPROBE ANALYSES OF CALCINE PARTICLES DISPERSED AFTER WASHING WITH WATER

$\mathrm{Fe}$

$\mathrm{Na}$

A]

$\mathrm{Mn}$

$\mathrm{Ni}$

Ca

0

S

Analys is

Conditions

\section{Magnification}

Raster Time (sec)
$10 \mathrm{~K}$

0.2
$10 \mathrm{~K}$

0.2

$10 \mathrm{~K}$

0.2

Composition in Weight Percent

$\begin{array}{cccc}\begin{array}{c}\text { Particle } \\ 1\end{array} & \begin{array}{c}\text { Particle } \\ 2\end{array} & \begin{array}{c}\text { Partici } \\ 3\end{array} \\ 41 . & & 40 . & 42 . \\ 2.5 & & 0.4 & 0.5 \\ 3.2 & & 3.9 & 5.5 \\ 9.6 & & 11 . & 8.8 \\ 4.2 & & 4.0 & 4.4 \\ 2.1 & & 2.4 & 2.5 \\ 8.8 & & 11 . & 9.0 \\ 0.01 & & 0.01 & 0.01\end{array}$

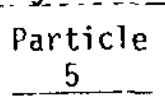

Particle - 6.

Sma $11^{\mathrm{a}}$ - 4 $-5$

27.

47.

43.

0.3

6.2

0.0

2.0

33.

0.2

15.

6.1

2.8

1.0

4.7

0.06

9.4

2.3

7.8

5.0

1.8

3.4

0.04

4.5

1.8

13.

0.02

8.8

3.8

2.1

4.6

0.09

Particle 8

49.

0.09

4.4

9.8

6.5

2.0

4.5

0.06

aparticle was approximately $10 \mu \mathrm{m} \times 13 \mu \mathrm{m}$.

barticle was approximately $20 \mu \mathrm{m}$ in diameter. 


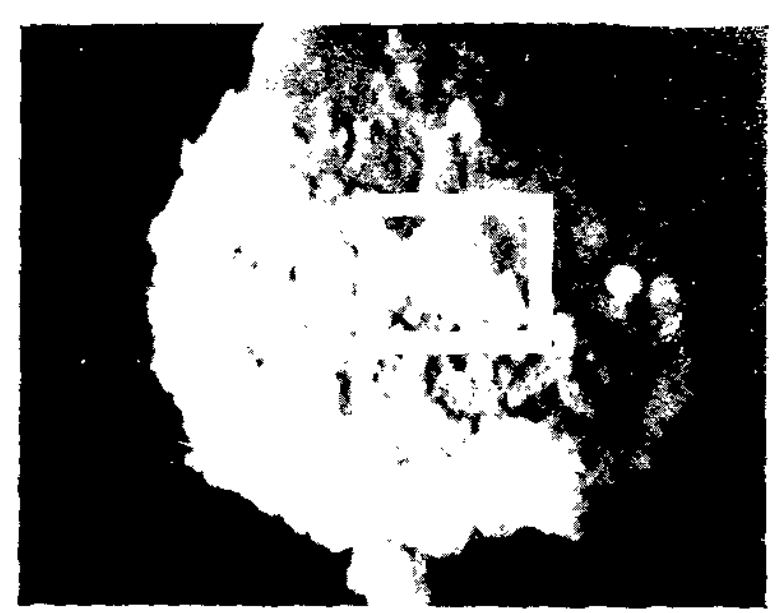

Mapped Area, $300 \mathrm{\mu m}^{2}$

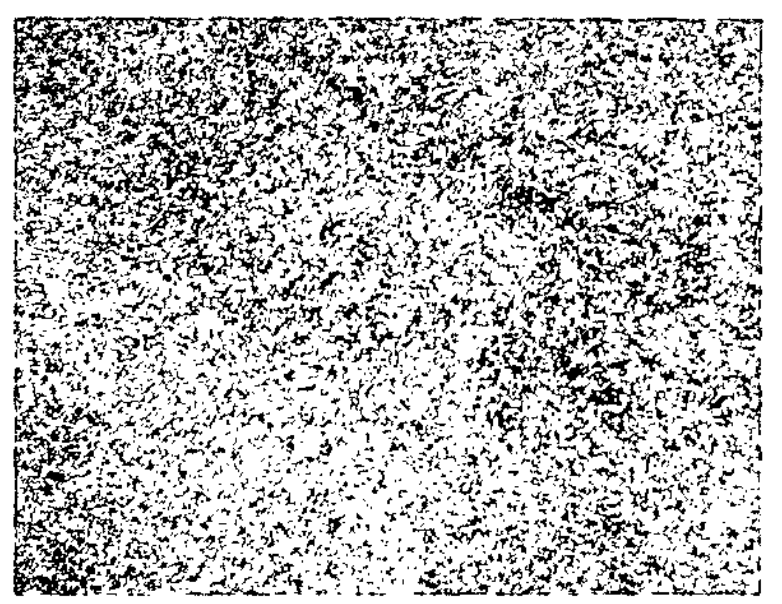

Iron, $300 \mathrm{~km}^{2}$

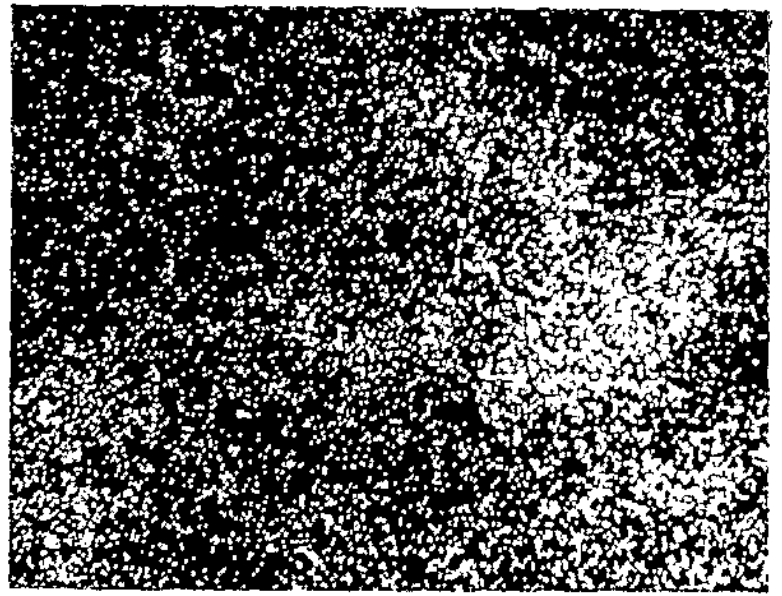

Manganese, $300 \mu \mathrm{m}^{2}$

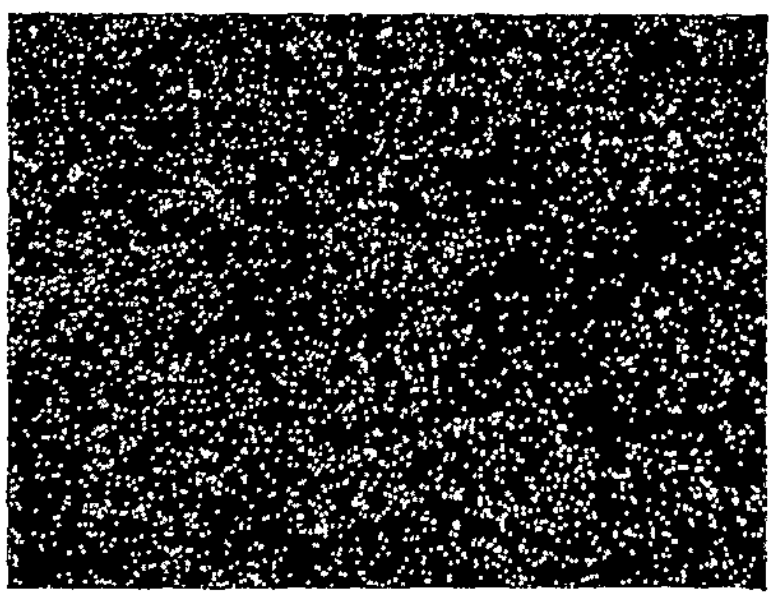

Nicke1, $300 \mu \mathrm{m}^{2}$

FIGURE 5A. X-Ray Maps of Water-Washed Particle 6 for Manganese, Iron, and Nickel 


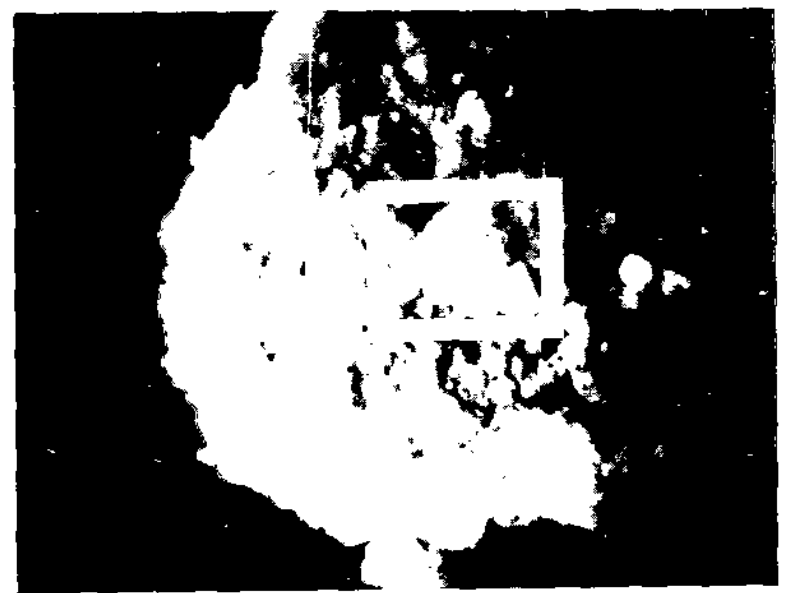

Mapped Area, $300 \mu^{2}$

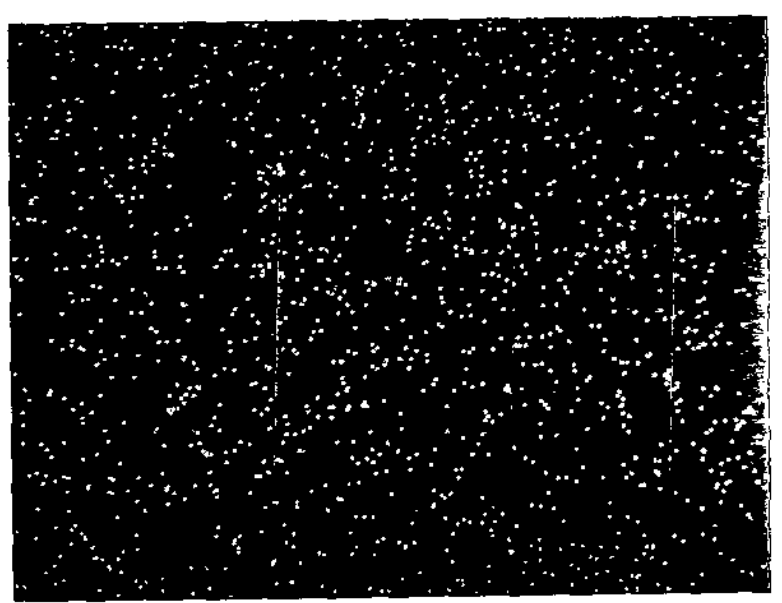

Calcium, $300 \mu \mathrm{m}^{2}$

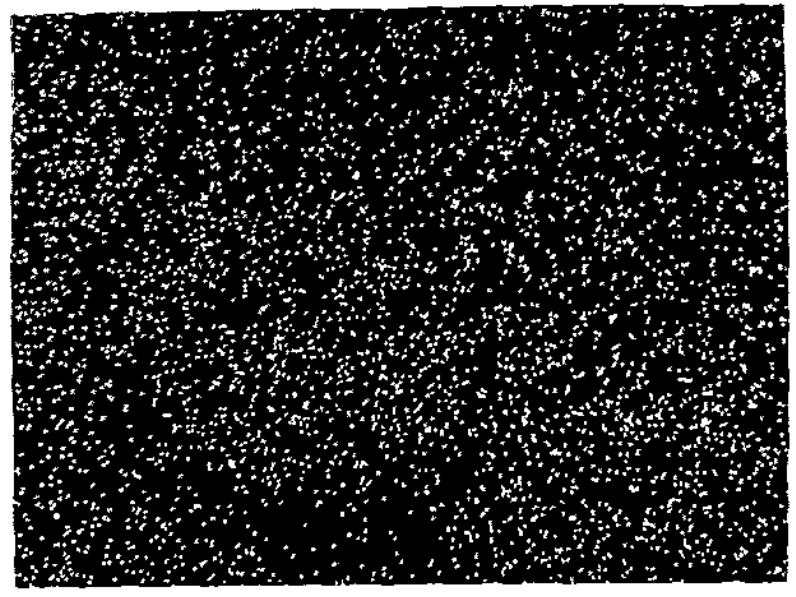

Aluminum, $300 \mu \mathrm{m}^{2}$

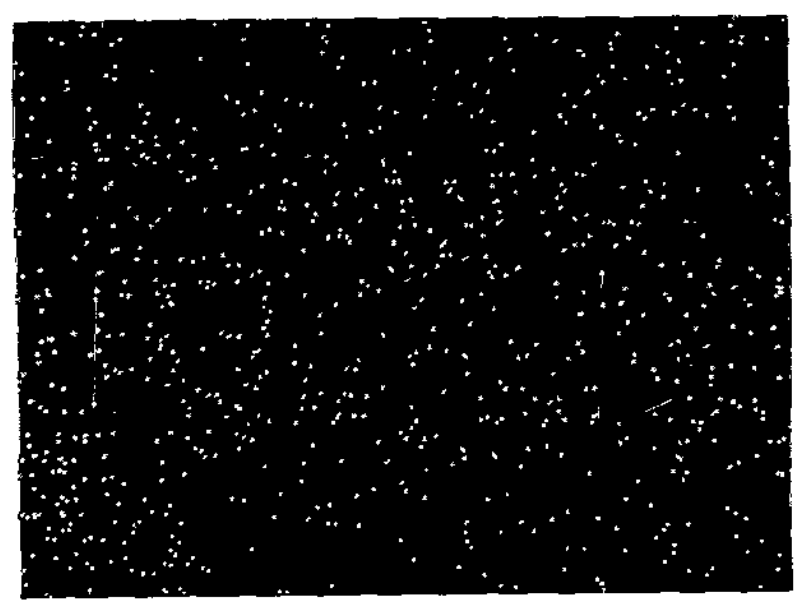

Sodium, $300 \mu \mathrm{m}^{2}$

FIGURE 5B. X-Ray Maps of Water-Washed Particle 6 for Aluminum, Calcium, and Sodium 
thermogravimetric analyzer sample chamber. The sampled gases were drawn continuously by the mass spectrometer vacuum system through the capillary tube and then into the mass spectrometer. The gas flow rate was appropriately adjusted by a flow-control valve on the capillary tube. Mass spectra of the evolved gases were recorded every 30 seconds as the sample vas heated at about $10^{\circ} \mathrm{C} / \mathrm{min}$ from room temperature to $1000^{\circ} \mathrm{C}$.

\section{Gases Evolved from Calcine}

Thermogravimetric and evolved gas analyses were run on a sample of calcine which had been dried overnight in a desiccator containing magnesium perchlorate desiccant. The TGA curve of Figure 6 shows the sample weight as it decreased during analysis. The initial and final sample weights were $31.6 \mathrm{mg}$ and $27.4 \mathrm{mg}$, respectively. Peak heights of the mass spectra were measured at each relevant mass for the gases evolved from calcine. These experimental data are reported in Appendix 2. Evolved gas analysis (EGA) curves of peak height versus sample temperature from these data are shown in Figures 7 through 11 for mass numbers 18 , $28,30,32$, and 44 . The gases which have their major peaks at these mass numbers are respectively water, nitrogen and carbon monoxide, nitric oxide, oxygen, and carbon dioxide. The only other significant peak observed in the mass spectra was that for the purge gas helium. The peak height for nitrogen dioxide at mass 46 remained at background level throughout the analysis.

The evolved gas analyses can be evaluated quantitatively by defining evolved gas sensitivities according to Equation l. In this equation, the evolved gas sensitivity $S_{x}$ for gas $X$ is assumed to be constant during the course of the experiment. To

$$
(m g \text { of gas } x)=s_{x}\left(\begin{array}{ll}
\text { Net Area Under } \\
\text { EGA Curve for Gas } x
\end{array}\right)
$$

illustrate the application of Equation 1, the weight of water evolved from the sample during heating from room temperature to $150^{\circ} \mathrm{C}$ could be calculated by determining the net area under the EGA curve for water in the room temperature to $150^{\circ} \mathrm{C}$ region and by multiplying this area by the sensitivity for water.

Sensitivities were calculated for water, carbon dioxide, nitric oxide, and oxygen from the TGA-mass spectrometric analysis data. To calculate these sensitivities, the experimental data were organized into an appropriate form by defining ten temperature regions over the TGA range of room temperature to $1000^{\circ} \mathrm{C}$. The sample weight loss in each temperature region was determined from the TGA curve. The net peak area in each temperature region 


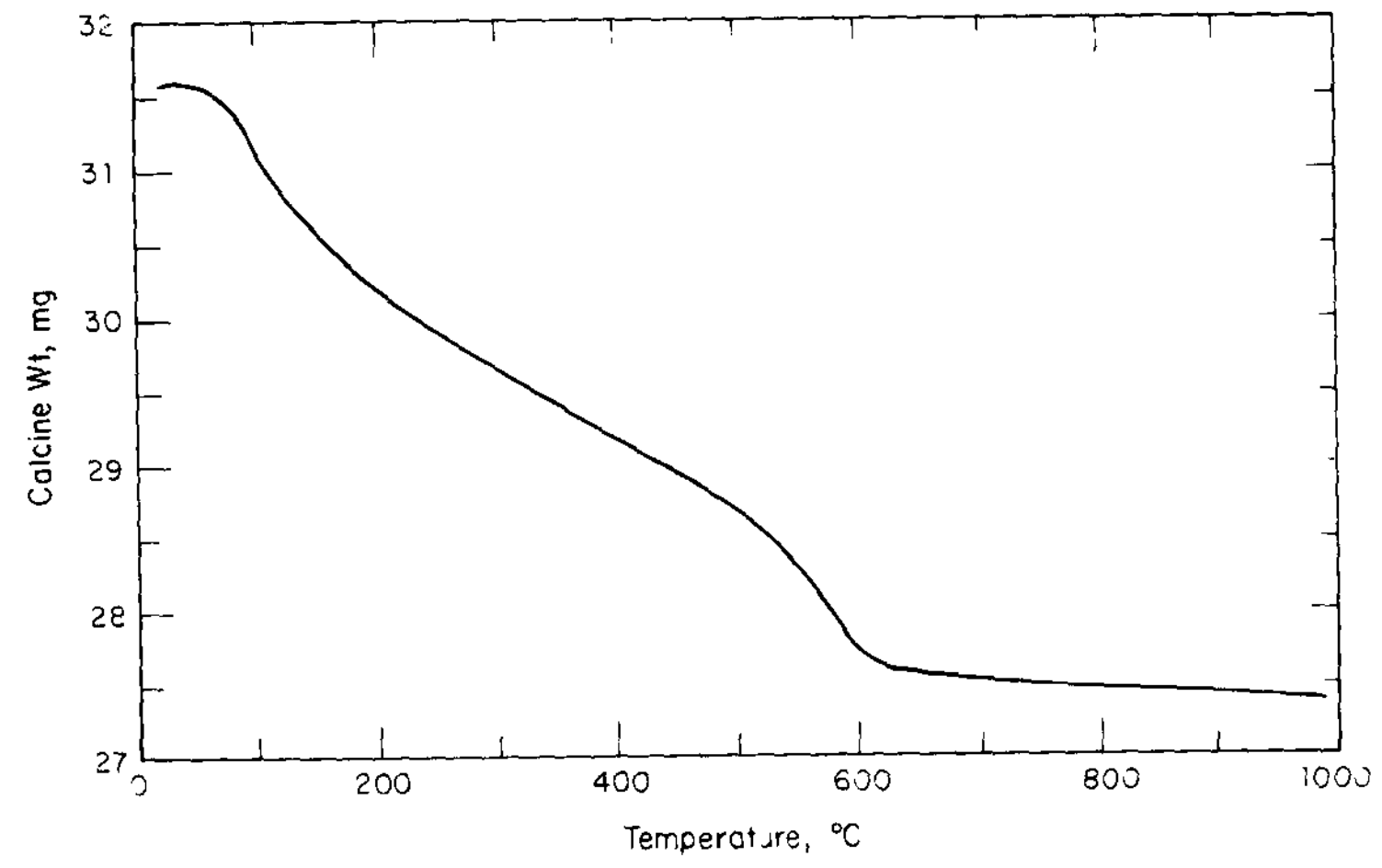

FIGURE 6. Thermogravimetric Analysis of Calcine 


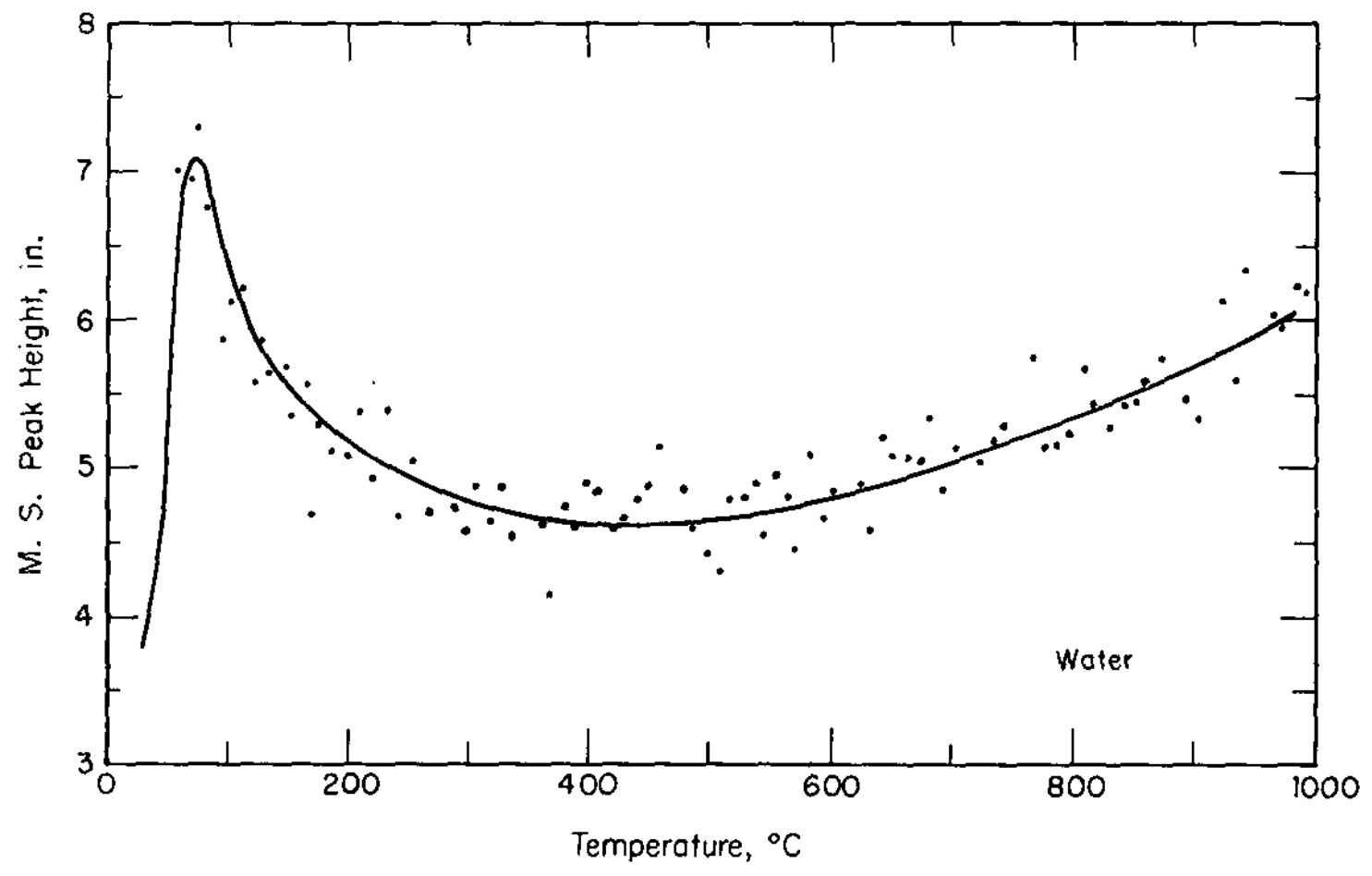

FIGURB 7. Evolved Gas Curve at Mass 18 for Calcine 


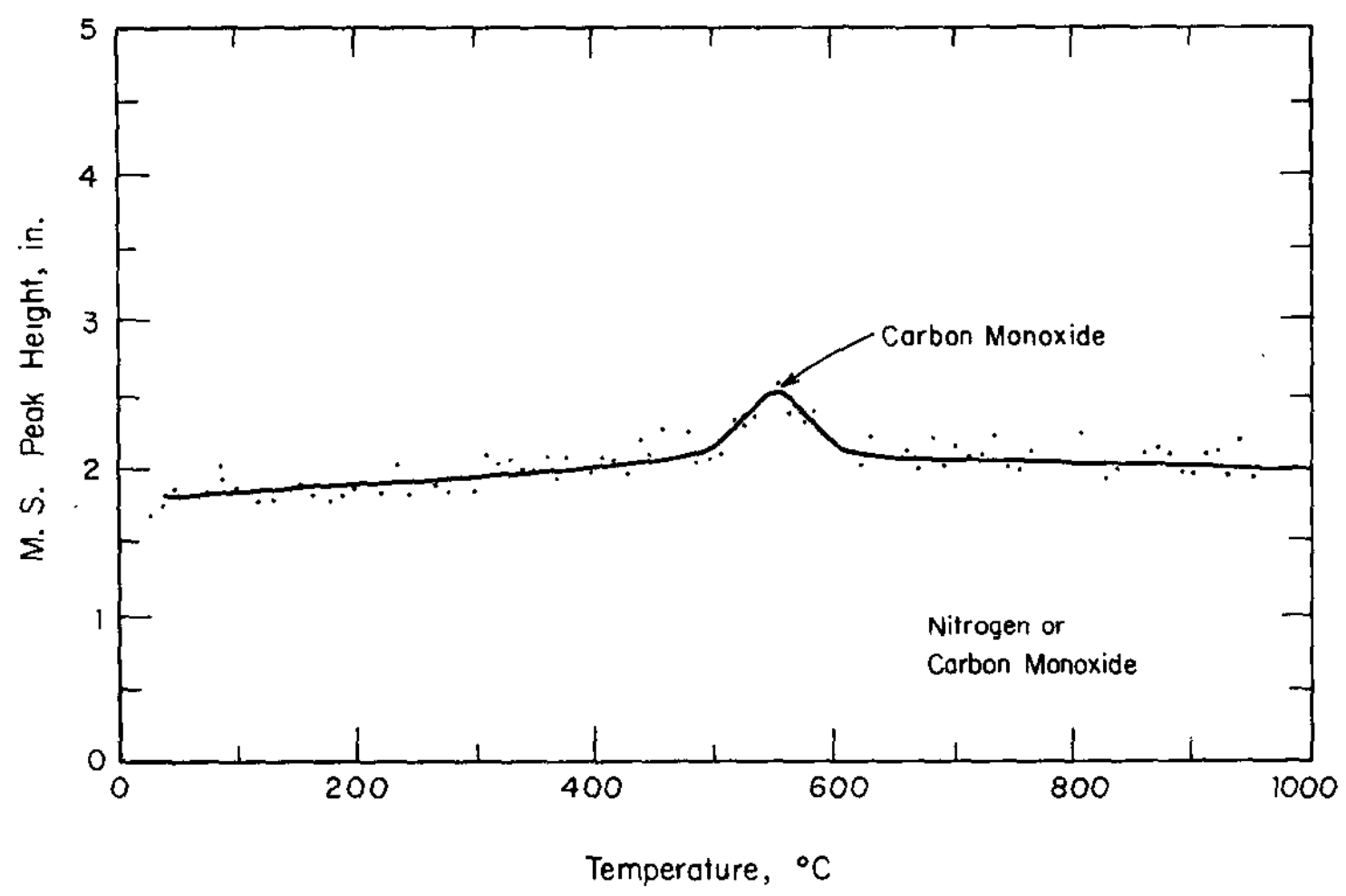

FIGURE 8. Evolved Gas Curve at Mass 28 for Calcine 


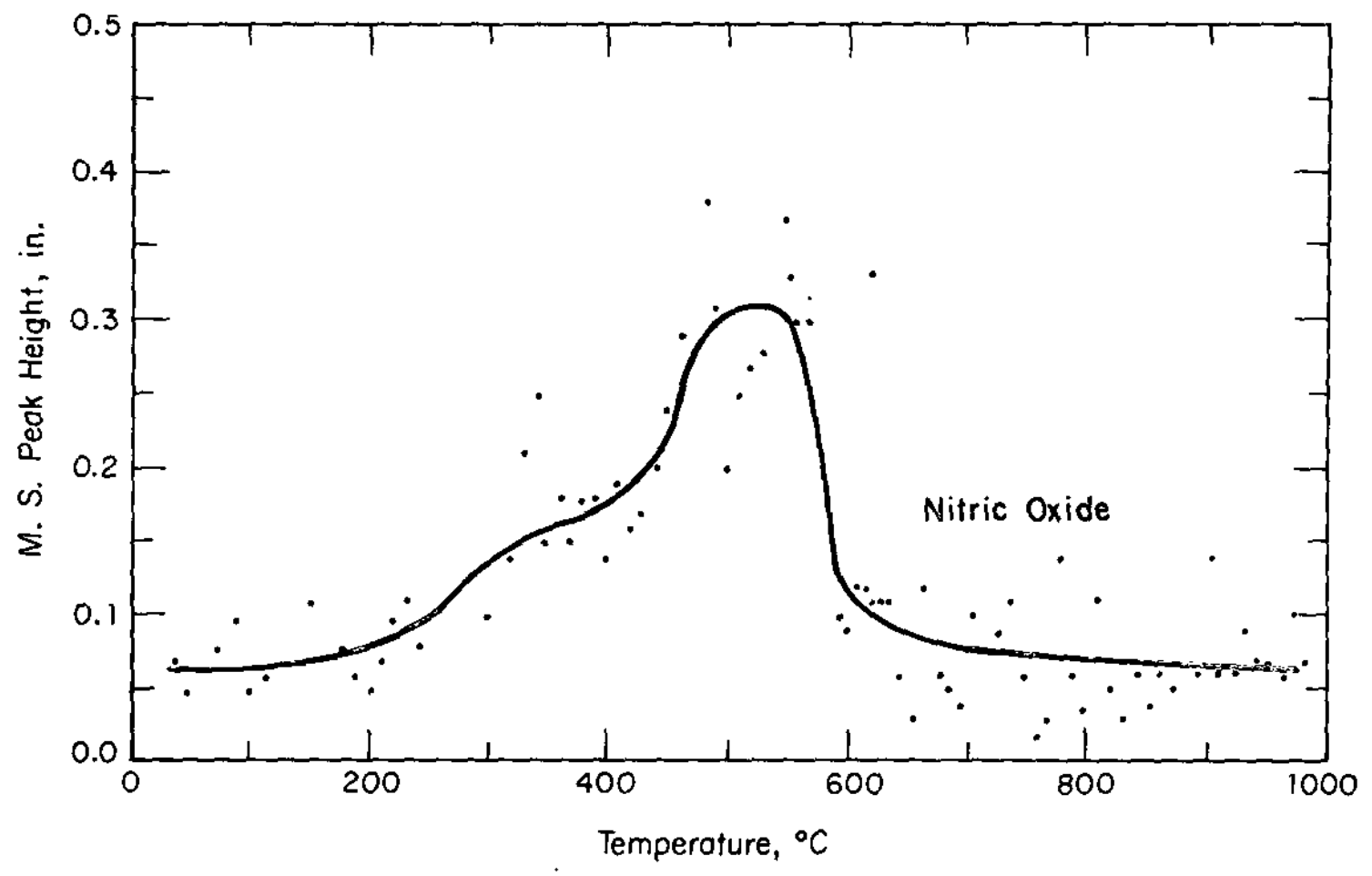

FIGURE 9. Evolved Gas Curve at Mass 30 for Calcine 


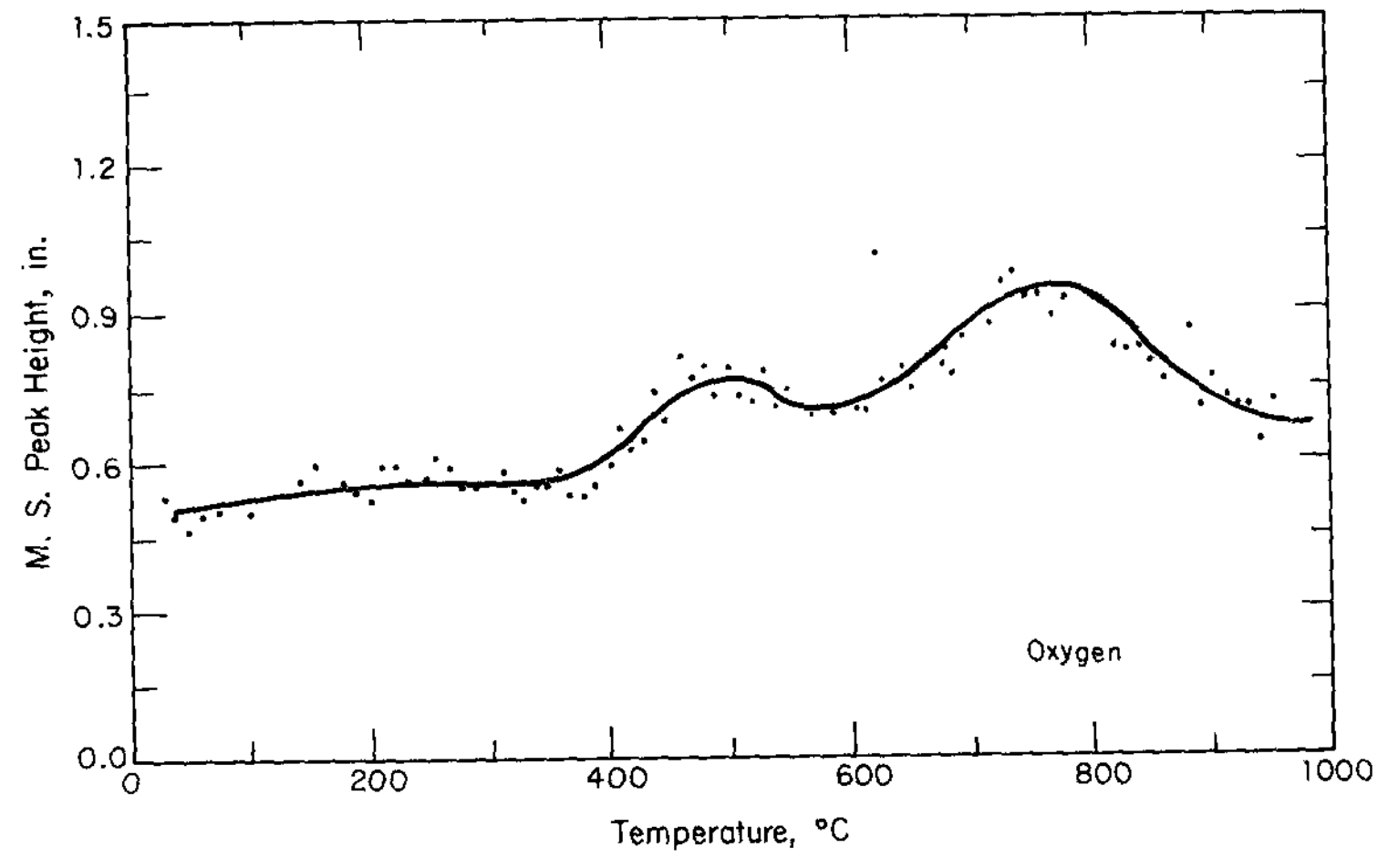

FIGURE 10. Evolved Gas Curve at Mass 32 for Calcine 


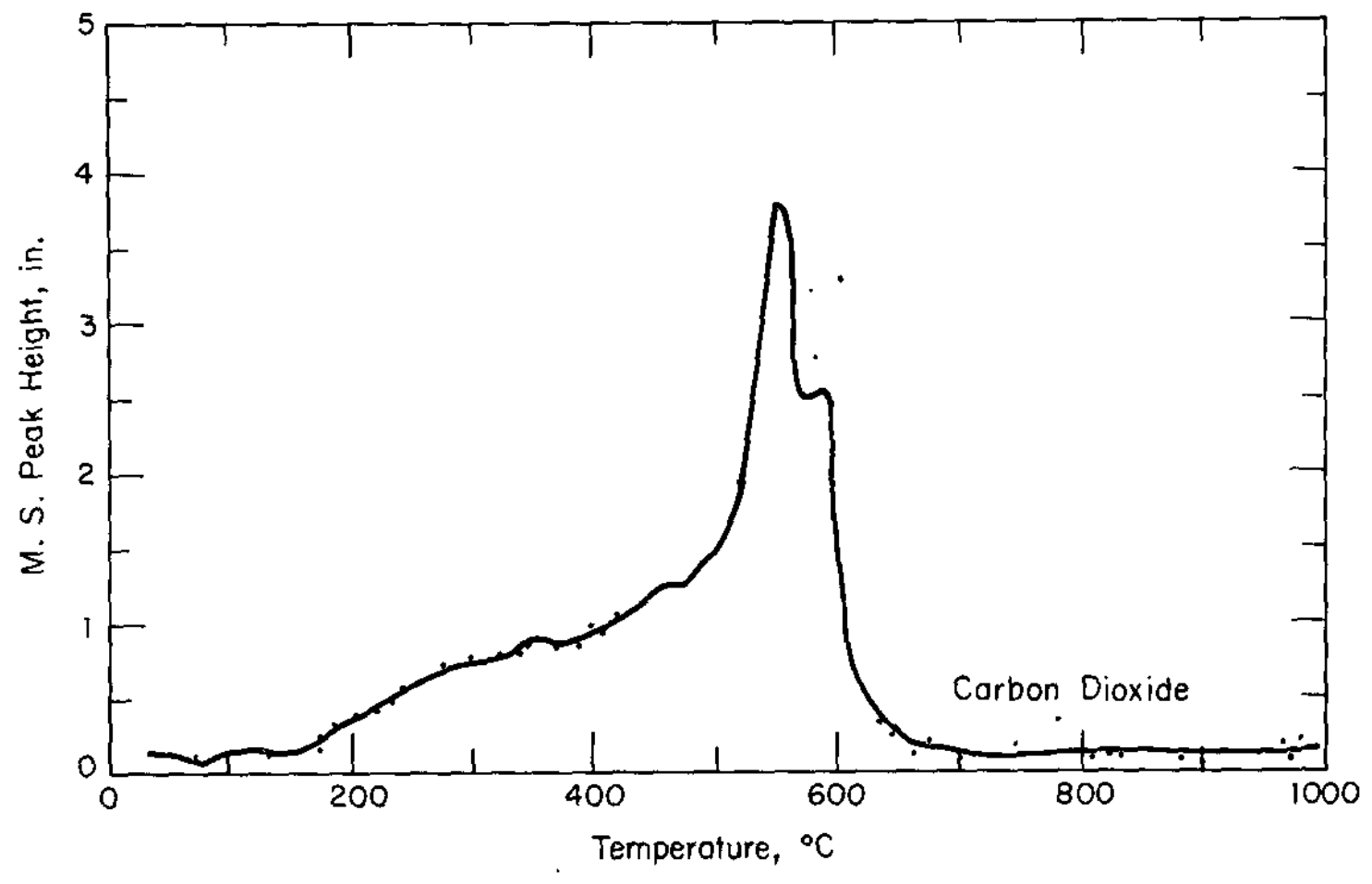

FIGURE 11. Evolved Gas Curve at Mass 44 for Calcine 
above a linear background was determined for each evolved gas from the evolved gas curves. These experimental data are reported for each temperature region in Table 6 . From these data, the evolved gas sensitivities were calculated for the calcine analysis as described in Appendix 3. The sensitivities and their estimated standard deviations are reported in Table 7 .

The reliability of the sensitivities was demonstrated by comparing the calculated weight loss for each temperature region with the measured weight loss determined experimentally during the TGA analysis. The calculated weight losses were evaluated from the net peak areas of Table 6 and the sensitivities of Table 7 by using Equation 1. The calculated and measured weight losses are compared in Table 8 and in Figure 12. If the calculated and measured weight losses agreed exactly, all of the data points of Figure 12 would lie on the line of unit slope through the origin. Since all of the experimental points lie relatively close to the line, the reliability of the calculated sensitivities is demonstrated for the calcine analysis. The large uncertainty in the sensitivity for nitric oxide does not significantly affect the calculated weights for each temperature region because the nitric oxide amounts to only two percent of the evolved gases.

The data of Table 8 show that approximately $6.1 \%$ of the calcine weight was evolved as water and that $6.1 \%$ was evolved as carbon dioxide. Nitric oxide and oxygen, respectively, accounted for approximately $0.3 \%$ and $0.6 \%$ of the calcine weight.

The evolved gas curve at mass 18 for water in calcine shows that water evolution begins at essentially room temperature, reaches a maximum of about $70^{\circ} \mathrm{C}$, and continues at a decreasing rate to approximately $500^{\circ} \mathrm{C}$. The slow continuous loss of water during isobaric heating is characteristic of hydrous oxides which trap water during precipitation and have no definite stoichiometric combination. 2 The relative amount of water in the calcine. is indicated by the molar ratio of water to iron. This ratio was calculated from the data of Tables 1 and 8 to be 0.81 . For comparison, the ratio for $\mathrm{Fe}_{2} \mathrm{O}_{3} \cdot \mathrm{H}_{2} \mathrm{O}$ is 0.50 .

The evolved gas curve for mass 44 shows that gas evolution begins at about $150^{\circ} \mathrm{C}$. The rate of evolution increases rather uniformly to about $500^{\circ} \mathrm{C}$ and then increases sharply with maximum evolution occurring at $550^{\circ} \mathrm{C}$. Above $550^{\circ} \mathrm{C}$, the evolution rate decreases rapidly until at $700^{\circ} \mathrm{C}$ all of the gas has been evolved. A small shoulder occurs on the evolved gas curve at about $590^{\circ} \mathrm{C}$. Since the shoulder has been observed in each of the two evolved gas analyses of calcine, it is presumably real. The gas evolutions at $550^{\circ} \mathrm{C}$ and at $590^{\circ} \mathrm{C}$ are attributed to carbon dioxide from thermal decomposition of carbonate species existing in different environments, for example, associated with different cations. The 
TABLE 6

\section{EXPERIMENTAL DATA FOR CALCINE ANALYSIS ORGANIZED} FOR SENSITIVITY CALCULATIONS

\begin{tabular}{|c|c|c|c|c|c|c|}
\hline \multirow{2}{*}{$\begin{array}{c}\text { Temperature } \\
\text { Region } \\
\end{array}$} & \multirow{2}{*}{$\begin{array}{l}\text { Temperature } \\
\text { Range, }{ }^{\circ} \mathrm{C}\end{array}$} & \multicolumn{4}{|c|}{ Net Peak Areas, Inch $-{ }^{\circ} \mathrm{C}$} & \multirow{2}{*}{$\begin{array}{l}\text { Wt. Loss, } \\
\mathrm{Mg}\end{array}$} \\
\hline & & $\mathrm{H}_{2} \mathrm{O}$ & $\mathrm{CO}_{2}$ & NO & $\underline{\mathrm{O}_{2}}$ & \\
\hline 1 & RT -100 & 140 & 0.0 & 0.0 & 0.0 & 0.45 \\
\hline 2 & $100-200$ & 163 & 9.5 & 0.0 & 0.0 & 0.92 \\
\hline 3 & $200-300$ & 70 & 46.6 & 3.26 & 0.0 & 0.58 \\
\hline 4 & $300-400$ & 29 & 75.0 & 8.43 & 1.7 & 0.48 \\
\hline 5 & $400-500$ & 13 & 110. & 16.4 & 15.2 & 0.49 \\
\hline 6 & $500-600$ & 1.6 & 258. & 18.3 & 17.8 & 0.95 \\
\hline 7 & $600-700$ & 0.0 & 37.4 & 3.0 & 21.3 & 0.18 \\
\hline 8 & $700-800$ & 0.0 & 5.8 & 0.8 & 33.8 & 0.07 \\
\hline 9 & $800-900$ & 0.0 & 0.0 & 0.0 & 26.3 & 0.05 \\
\hline 10 & $900-1000$ & 0.0 & 0.0 & 0.0 & 10.7 & 0.03 \\
\hline Total & & 416.6 & 542.3 & 50.19 & 126.8 & 4.20 \\
\hline
\end{tabular}


TABLE 7

EVOLVED GAS SENSITIVITIES FOR CALCINE ANALYSIS

$\begin{array}{lll}\text { Gas } & \begin{array}{l}\text { Sensitivity } \\ \text { mg/inch }{ }^{\circ} \mathrm{C}\end{array} & \begin{array}{c}\text { Standard Deviation } \\ \mathrm{mg} / \text { inch }\end{array}{ }^{\circ} \mathrm{C}\end{array}$

*The large uncertainty in the sensitivity for nitric oxide does not significantly affect the calculated weights for each temperature region because nitric oxide amounts to only two percent of the evolved gases. 
TABLE 8

IEST OF EVOLVEO GAS SENSITIVITIES FOR CALCINE ANALYSIS

\begin{tabular}{|c|c|c|c|c|c|c|c|}
\hline \multirow{2}{*}{$\begin{array}{l}\text { Temp. } \\
\text { Region }\end{array}$} & \multirow{2}{*}{$\begin{array}{l}\text { Temp. } \\
\text { Range, }{ }^{\circ} \mathrm{C}\end{array}$} & \multicolumn{4}{|c|}{ Gas Evolved From Sample, mg } & \multicolumn{2}{|c|}{ Wt Loss, mg } \\
\hline & & $\underline{\mathrm{H}_{2} \mathrm{O}}$ & $\mathrm{CO}_{2}$ & No & $\underline{0}_{2}$ & Measured & Calc'd \\
\hline 1 & RT -100 & 0.651 & & & & 0.45 & 0.651 \\
\hline 2 & $100-200$ & 0.758 & 0.034 & & & 0.92 & 0.792 \\
\hline 3 & $200-300$ & 0.326 & 0.166 & 0.006 & & 0.58 & 0.498 \\
\hline 4 & $300-400$ & 0.135 & 0.268 & 0.014 & 0.002 & 0.48 & 0.419 \\
\hline 5 & $400-500$ & 0.060 & 0.393 & 0.028 & 0.022 & 0.49 & 0.503 \\
\hline 6 & $500-600$ & 0.007 & 0.921 & 0.031 & 0.026 & 0.95 & 0.985 \\
\hline 7 & $600-700$ & & 0.134 & 0.005 & 0.031 & 0.18 & 0.170 \\
\hline 8 & $700-800$ & & 0.021 & 0.001 & 0.049 & 0.07 & 0.071 \\
\hline 9 & $800-900$ & & & & 0.038 & 0.05 & 0.038 \\
\hline 10 & $900-1000$ & & . & & 0.015 & 0.03 & 0.015 \\
\hline Total & & 1.937 & 1.937 & 0.085 & 0.183 & 4.20 & 4.142 \\
\hline Wt $\%$ of & cine & 6.13 & 6.13 & 0.27 & 0.58 & 13.29 & 13.11 \\
\hline & & $\begin{array}{l}\mathrm{S}_{\mathrm{H}_{2} \mathrm{O}} \\
\mathrm{S}_{\mathrm{CO}_{2}} \\
\mathrm{~S}_{\mathrm{NO}} \\
\mathrm{S}_{\mathrm{O}_{2}}\end{array}$ & $\begin{array}{l}=4.65 \times \\
=3.57 \times \\
=1.7 \times \\
=1.44 \times\end{array}$ & $\begin{array}{l}-3 \mathrm{mg} / \mathrm{i} \\
-3 \\
-3 \\
-3\end{array}$ & ${ }^{\circ} \mathrm{C}$ & & \\
\hline
\end{tabular}




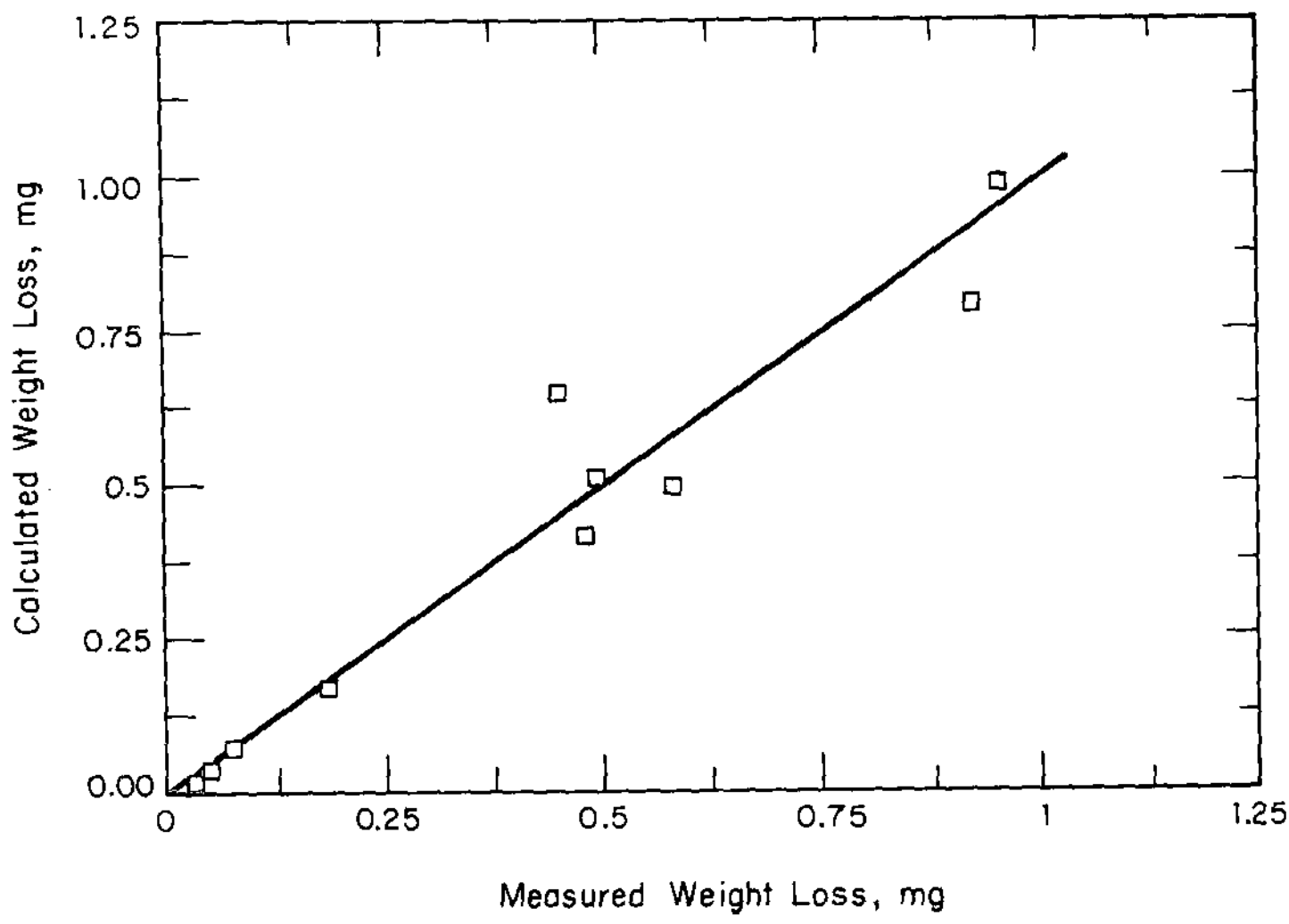

FIGURE 12. Test of Evolved Gas Sensitivities for Calcine Analysis 
gas evolution at lower temperatures is attributed to carbon dioxide from decomposition of carbonate or bicarbonate species. Alternatively, the gas evolved at lower temperatures could be nitrous oxide from nitrate decomposition. This latter possibility, however, seems very unlikely, and it is not supported by the experimental data. The small peak in the evolved gas curve for mass 28 (nitrogen or carbon monoxide) corresponds exactly to the maximum carbon dioxide evolution, and is of the magnitude expected for the mass 28 peak due to the carbon dioxide.

Thermal decomposition of nitrate species in calcine was expected to produce nitric oxide, oxygen, and nitrogen dioxide. These gases exist in equilibrium according to Equation 2, so that the relative quantities of each gas is determined by the equilibrium temperature.

$$
2 \mathrm{NO}+\mathrm{O}_{2} \rightleftharpoons 2 \mathrm{NO}_{2}+\text { heat }
$$

The mass spectra for the calcine analysis showed no significant peak at mass 46 for nitrogen dioxide and indicated that nitrogen dioxide was not present in the evolved gases at a detectable concentration. However, the evolved gas curves for mass 30 and mass 32 both showed peaks at approximately $500^{\circ} \mathrm{C}$. Although the nitric oxide and oxygen peaks are rather small, their simultaneous detection indicates that nitrate decomposition occurs at about $500^{\circ} \mathrm{C}$ for calcine.

In addition to the oxygen at $500^{\circ} \mathrm{C}$ from nitrate decomposition, the evolved gas curve for mass 32 shows a broad oxygen peak at about $775^{\circ} \mathrm{C}$. The peak is attributed to conversion of $\mathrm{Fe}_{2} \mathrm{O}_{3}$ to $\mathrm{Fe}_{3} \mathrm{O}_{4}$ and perhaps of $\mathrm{MnO}_{2}$ to $\mathrm{Mn}_{3} \mathrm{O}_{4}$. These conversions are supported by the $x$-ray diffraction analysis which showed that a spinel-type oxide $\left(\mathrm{M}_{3} \mathrm{O}_{4}\right)$ was the major crystalline phase in the calcine after heating to $1000^{\circ} \mathrm{C}$ during the thermogravimetric and evolved gas analyses.

\section{Gases Bvolved from Sludge}

Thermogravimetric and evolved gas analyses were run on a sample of sludge that had been collected by vacuum filtration from the calciner feed slurry. The sludge was dried overnight in a desiccator containing magnesium perchlorate desiccant prior to these analyses. The analytical procedure for sludge analysis was identical to that for calcine analysis, but the gas flow rates for the helium purge through the TGA chamber and the gas flow rate to the mass spectrometer may have been somewhat different from those for the calcine analysis. Gas flow rates were not quantitatively determined. The TGA curve for sludge analys is is shown in Fig-. ure 13. The initial and final sample weights were $55.2 \mathrm{mg}$ and 


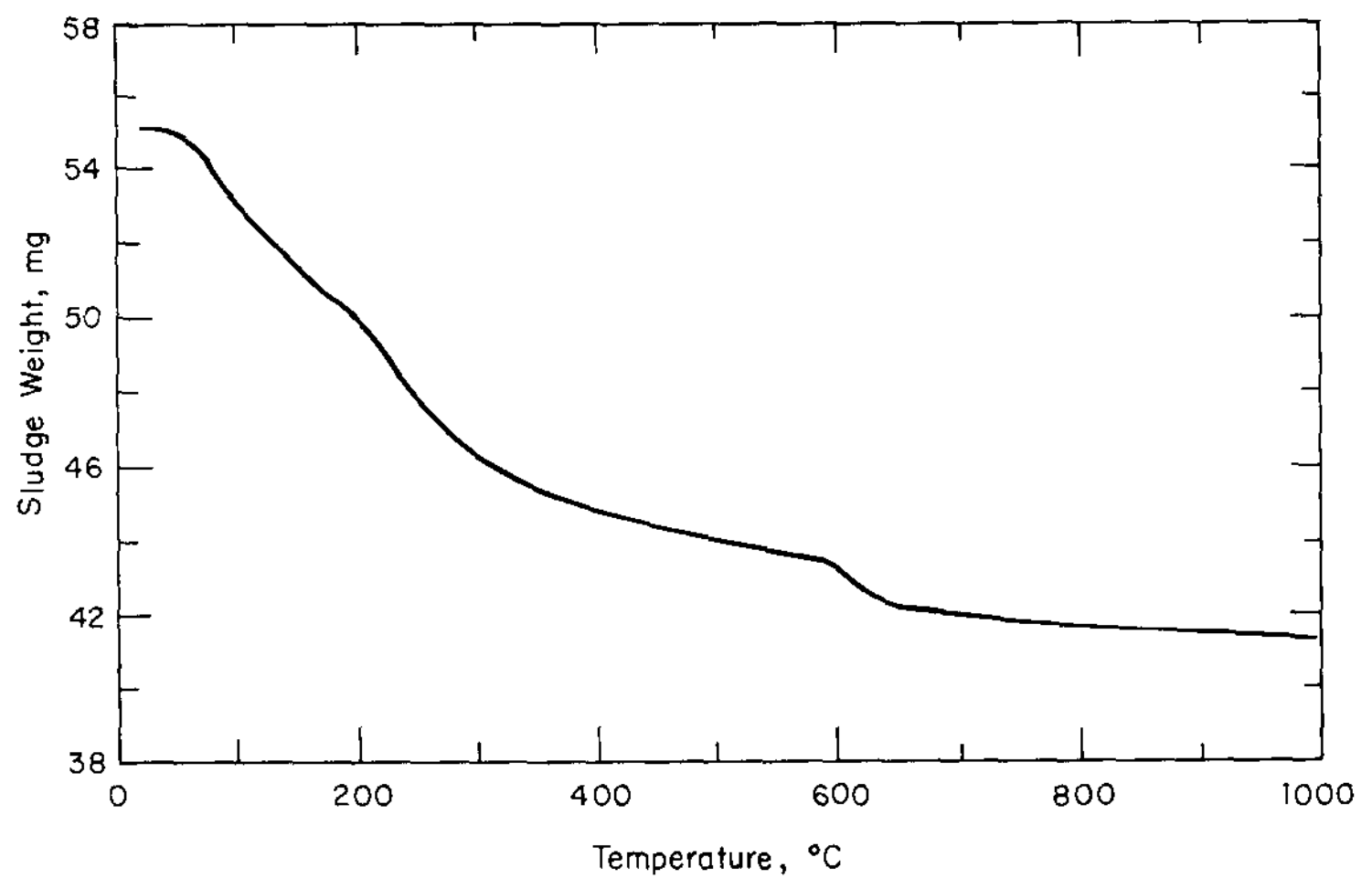

FIGURE 13. Thermogravimetric Analysis of Sludge 
$41.5 \mathrm{mg}$, respectively. Peak heights of the mass spectra of gases evolved from sludge are reported in Appendix 2 for masses 18, 28, 30,32 , and 44. No significant peak was observed at mass 46 for nitrogen dioxide. Evolved gas curves for the sludge analysis are shown in Figures 14 through 18 .

The TGA weight loss data and the areas under the evolved gas curves above linear backgrounds are reported in Table 9 for ten temperature regions. From these data, the evolved gas sensitivities of Tables 10, Method 1, were calculated for the sludge analysis as described in Appendix 3. The negative value for the sensitivity of nitric oxide is obviously incorrect and arises because the calculated sensitivity for nitric oxide is very sensitive to small changes in the experimental data for water, carbon dioxide, and oxygen. The sensitivities for the evolved gases were then recalculated by Methods 2 and 3 to determine if the calculated sensitivities for water, carbon dioxide, and oxygen were significantly affected by uncertainty in the nitric oxide sensitivity. The sensitivities calculated by Methods 2 and 3 are also reported in Table 10 .

For Method 2, the sensitivity for nitric oxide was arbitrarily assumed to be $6 \times 10^{-3} \mathrm{mg} /$ inch ${ }^{\circ} \mathrm{C}$, the average of the sensitivities for water, carbon dioxide, and oxygen for Method 1. The TGA weight loss for each temperature region was then reduced by using Equation 1 to correct for the effect of nitric oxide. Sensitivities for water, carbon dioxide, and oxygen were then calculated by solving the three relevant simultaneous equations as described in Appendix 3.

For Method 3, the sensitivities were calculated by solving the three relevant simultaneous equations and completely disregarding the nitric oxide and its effect on weight loss.

Comparison of the sensitivities for water, carbon dioxide, and oxygen calculated by the three methods shows that their sensitivities are not greatly affected by uncertainty in the nitric oxide sensitivity. Consequently for subsequent discussion, the sensitivities for Method 2 will be considered most reliable. The reliability of the Method 2 sensitivities was demonstrated by comparing the calculated weight loss for each temperature region with the measured weight loss determined experimentally during the TGA analysis. The calculated and measured weight losses are compared in Table 11 and in Figure 19.

These data show that approximately $13.6 \%$ of the sludge weight was evolved as water and that $8.6 \%$ was evolved as carbon dioxide. Nitric oxide and oxygen respectively accounted for approximately $0.4 \%$ and $1.1 \%$ of the sludge weight. 


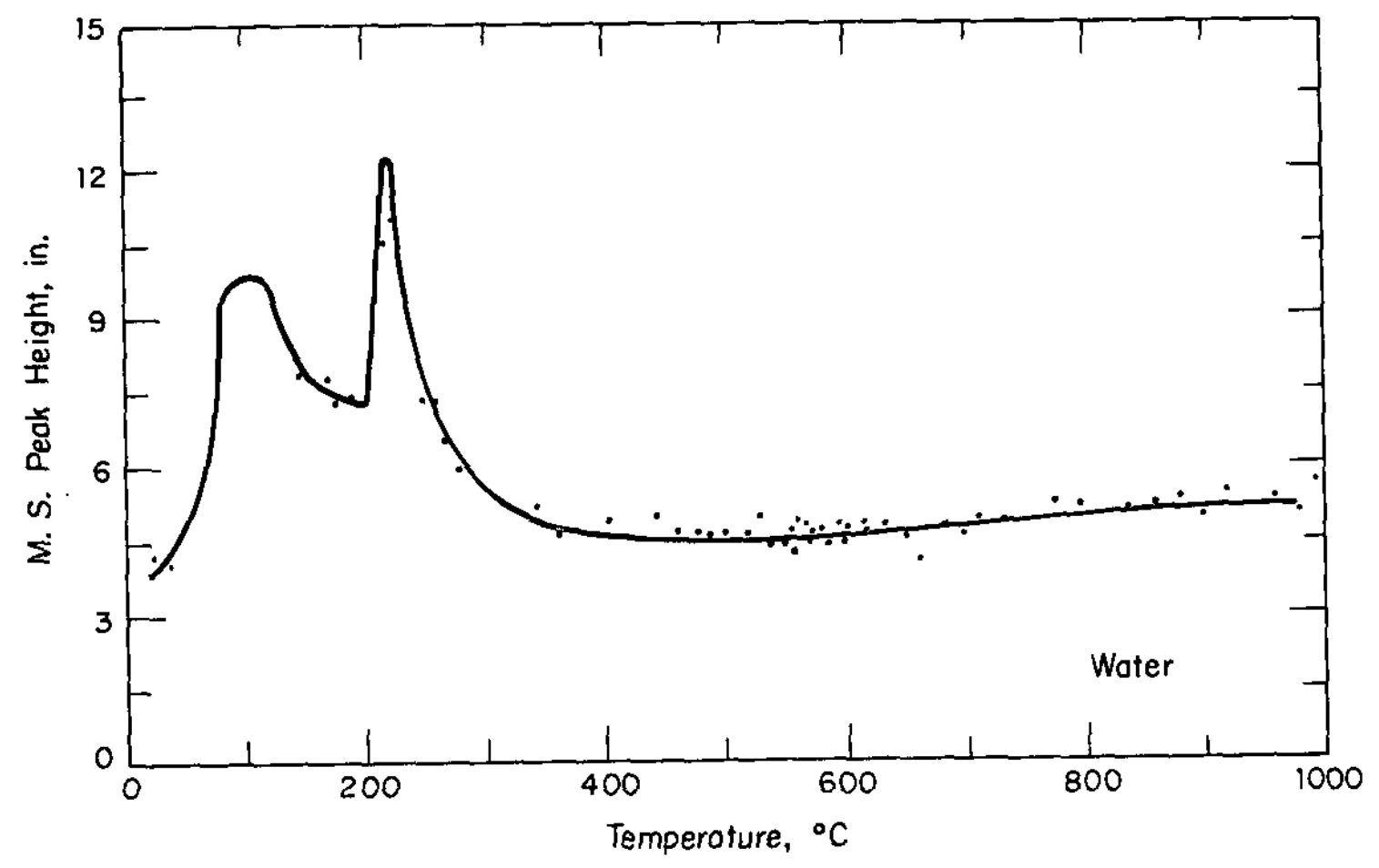

FIGURE 14. Evolved Gas Curve at Mass 18 for Sludge 


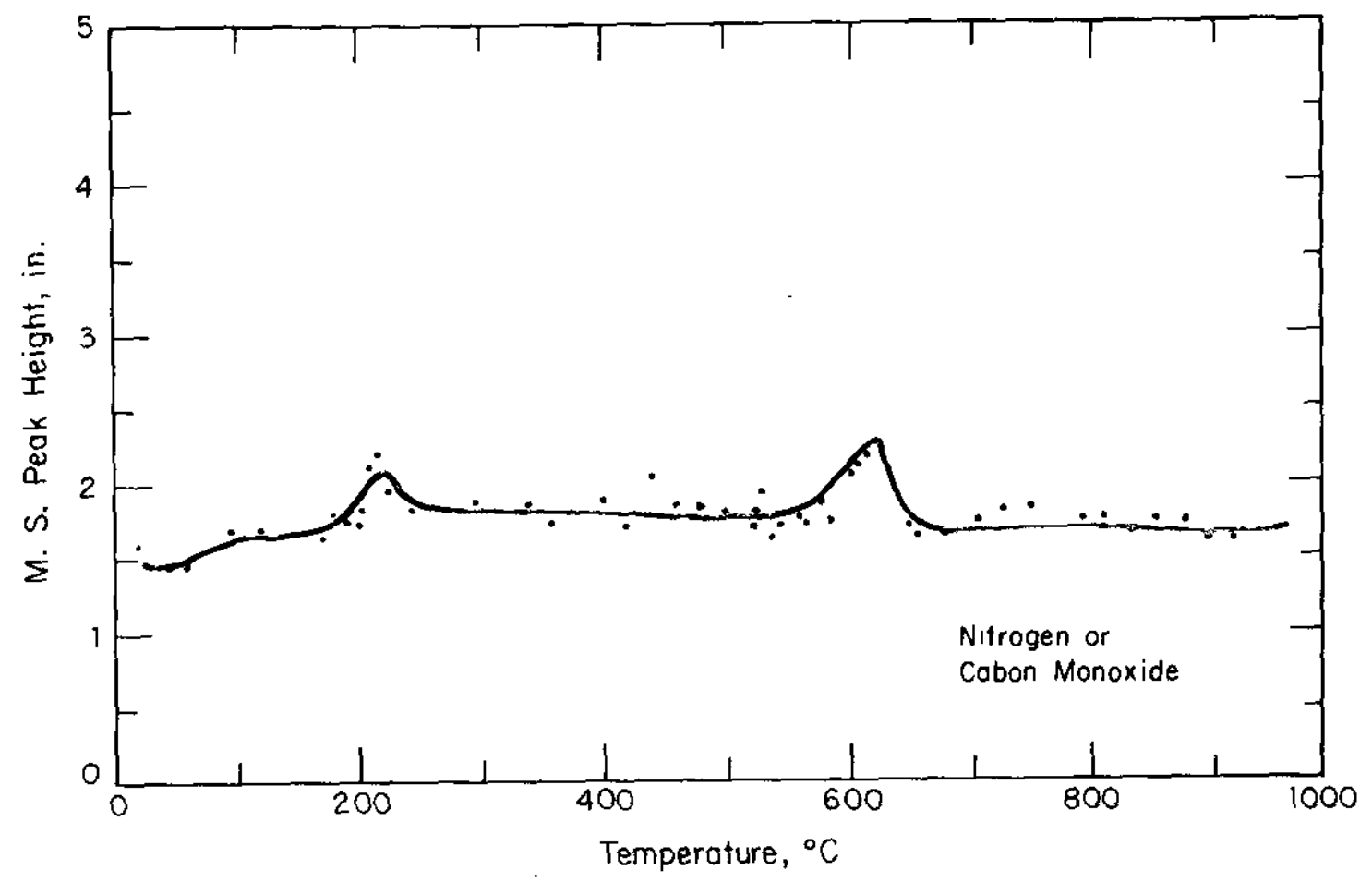

FIGURE 15. Evolved Gas Curve at Mass 28 for Sludge 


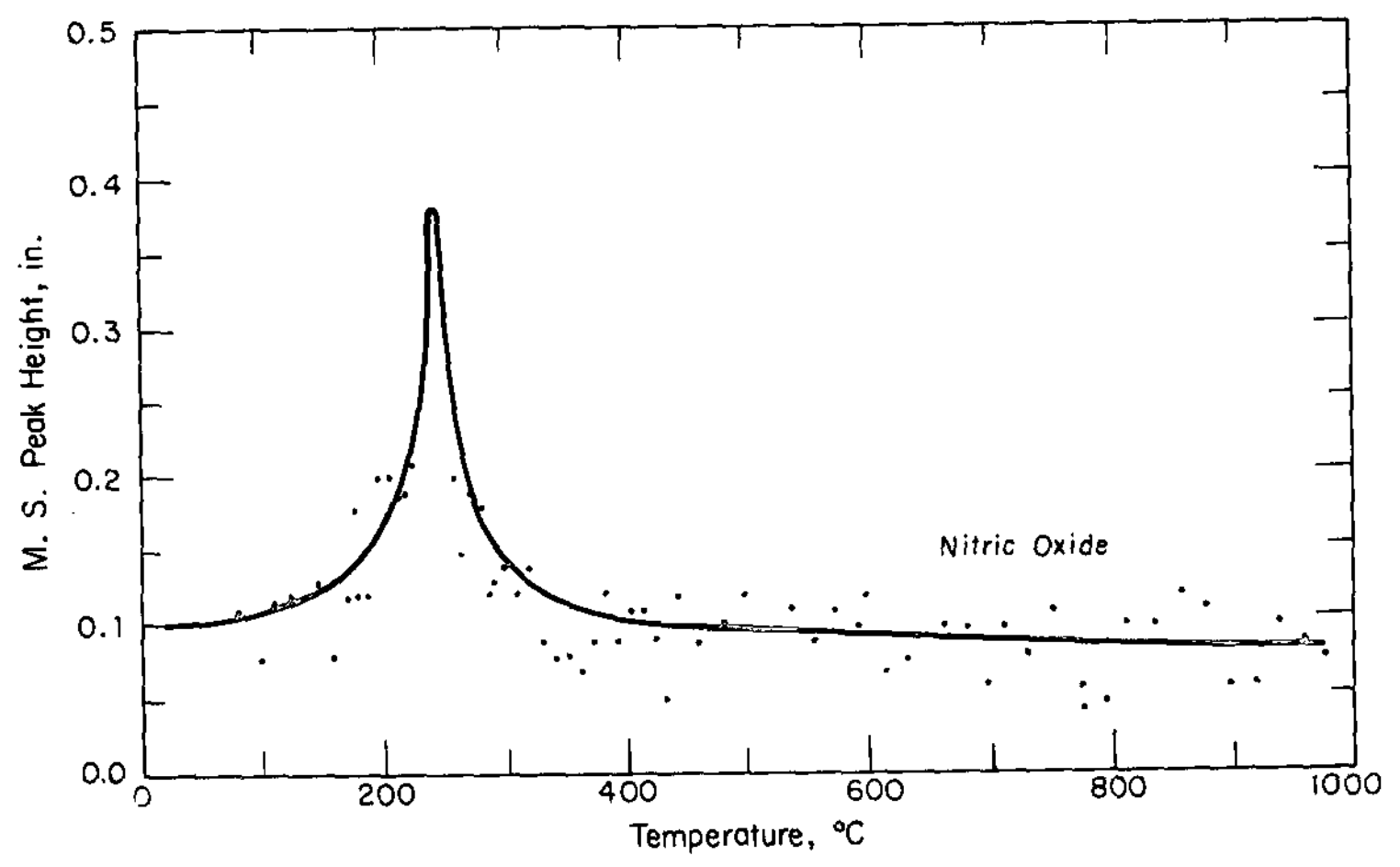

FIGURE 16. Evolved Gas Curve at Mass 30 for sludge 


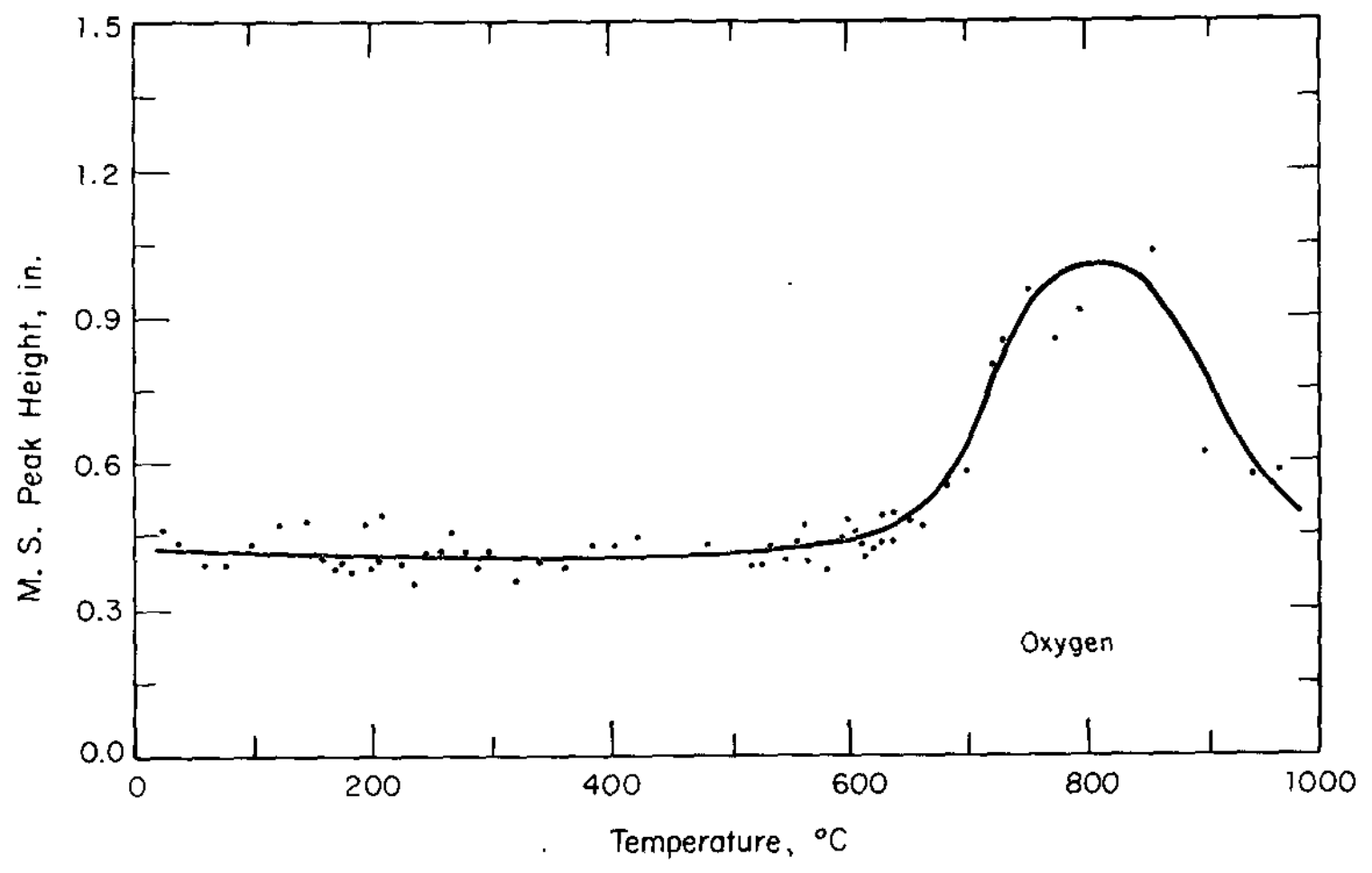

FIGURE 17. Evolved Gas Curve at Mass 32 for sludge 


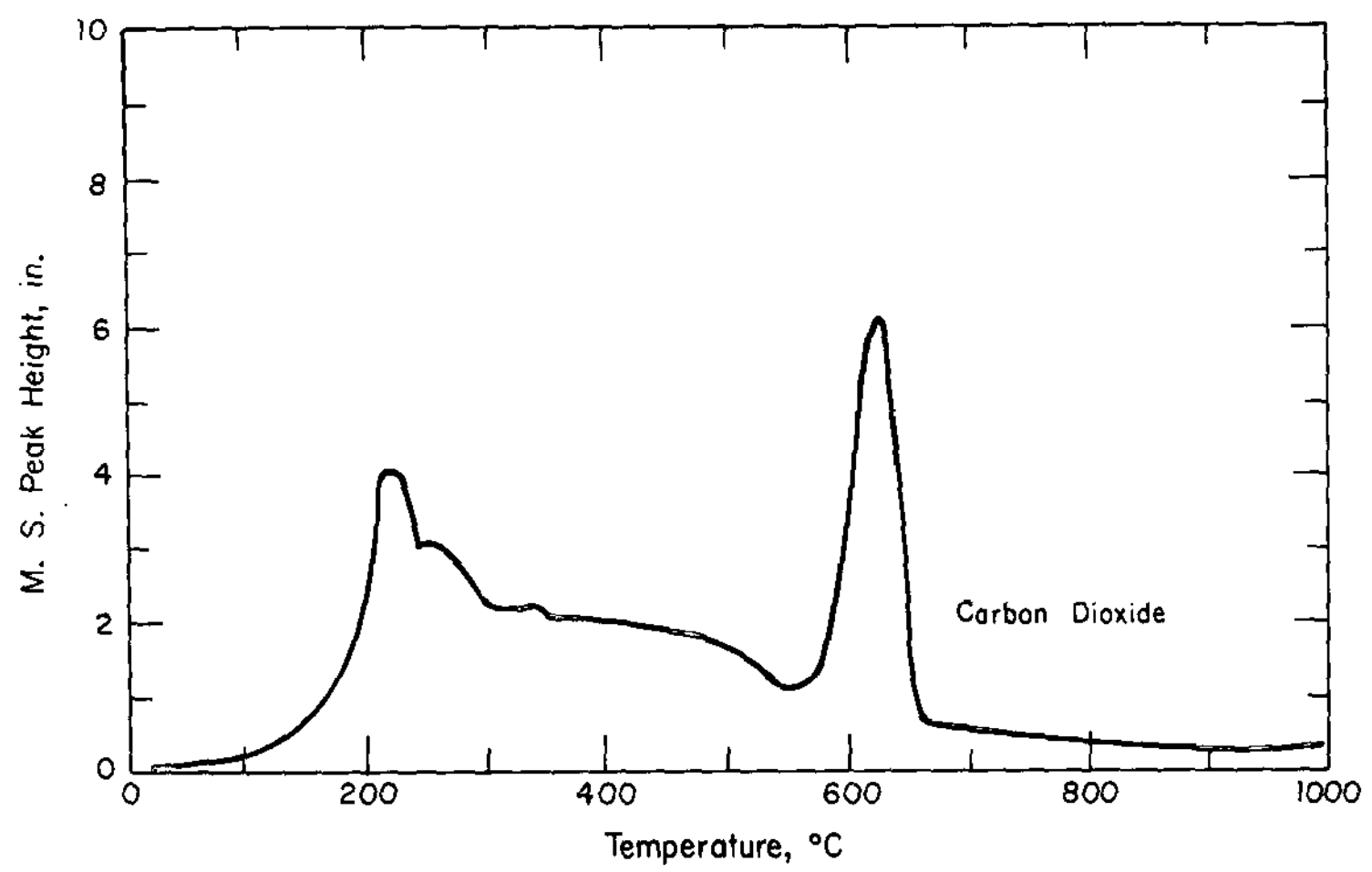

FIGURB 18. Evolved Gas Curve at Mass 44 for Sludge 


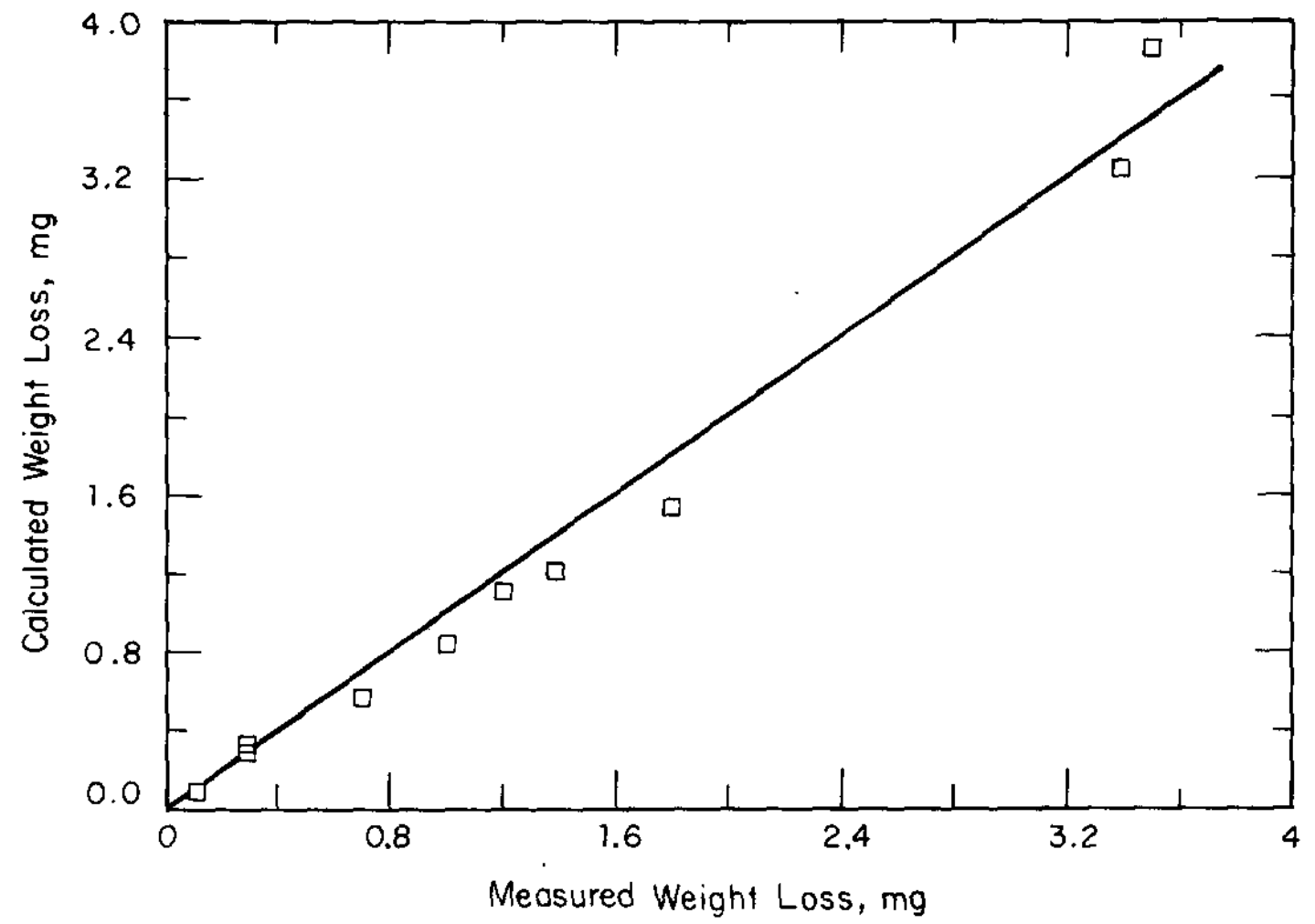

FIGURE 19. Test of Evolved Gas Sensitivities for sludge Analysis 
TABLE 9

EXPERIMENTAL DATA FOR SLUDGE ANALYSIS ORGANIZED FOR SENSITIVITY CALCULATIONS

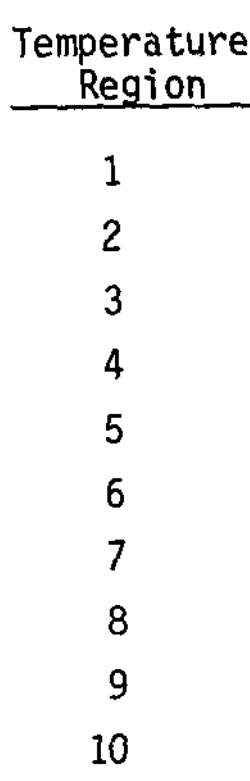

Total

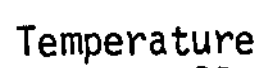

Range, ${ }^{\circ} \mathrm{C}$

$$
\text { RT-100 }
$$

$100-200$

200-300

$300-400$

400-500

$500-600$

$600-700$

$700-800$

$800-900$

$900-1000$
Net Peak Areas, Inch ${ }^{\circ} \mathrm{C}$

\begin{tabular}{c}
\hline $\mathrm{H}_{2} \mathrm{O}$ \\
\hline 220. \\
427. \\
370. \\
56.8 \\
17.8 \\
0.0 \\
0.0 \\
0.0 \\
0.0 \\
0.0
\end{tabular}

1091.6

\begin{tabular}{r}
$\mathrm{CO}_{2}$ \\
\hline 4.3 \\
68.3 \\
303. \\
199. \\
175. \\
137. \\
267. \\
24.2 \\
6.6 \\
0.0
\end{tabular}

1184.4

NO

0.74

6.11

16.6

4.59

4.02

3.65

1.86

0.44

0.0

0.0

38.01
Wt. Loss, $\mathrm{mg}$

1.80

3.40

3.50

1.40

1.00

0.70

1.20

0.30

0.30

0.10

13.7 
TABLE 10

EVOLVED GAS SENSITIVITIES FOR SLUDGE ANALYSIS

Sensitivity, $\mathrm{mg} /$ inch $^{\circ} \mathrm{C}$

Gas

\section{Method \\ 1}

$\mathrm{H}_{2} \mathrm{O}$

$\mathrm{CO}_{2}$

NO

$\mathrm{O}_{2}$
Method

2

$6.88 \times 10^{-3}$

$4.01 \times 10^{-3}$

6. $\times 10^{-3}$

$5.34 \times 10^{-3}$
Method 3

$6.98 \times 10^{-3}$

$4.15 \times 10^{-3}$

Not Considered

$5.29 \times 10^{-3}$

Method 1: Solution of four simultaneous equations as for the calcine analysis.

Method 2: Solution of three simultaneous equations assuming $\mathrm{S}_{\mathrm{NO}}=6 . \times 10^{-3} \mathrm{mg} /$ inch ${ }^{\circ} \mathrm{C}$ to correct weight losses.

Method 3: Solution of three simultaneous equations completely disregarding the $\mathrm{NO}$ and its effect on weight losses. 
TABLE 11

\section{TEST OF EVOLVED GAS SENSITIVITIES FOR SLUDGE ANALYSIS}

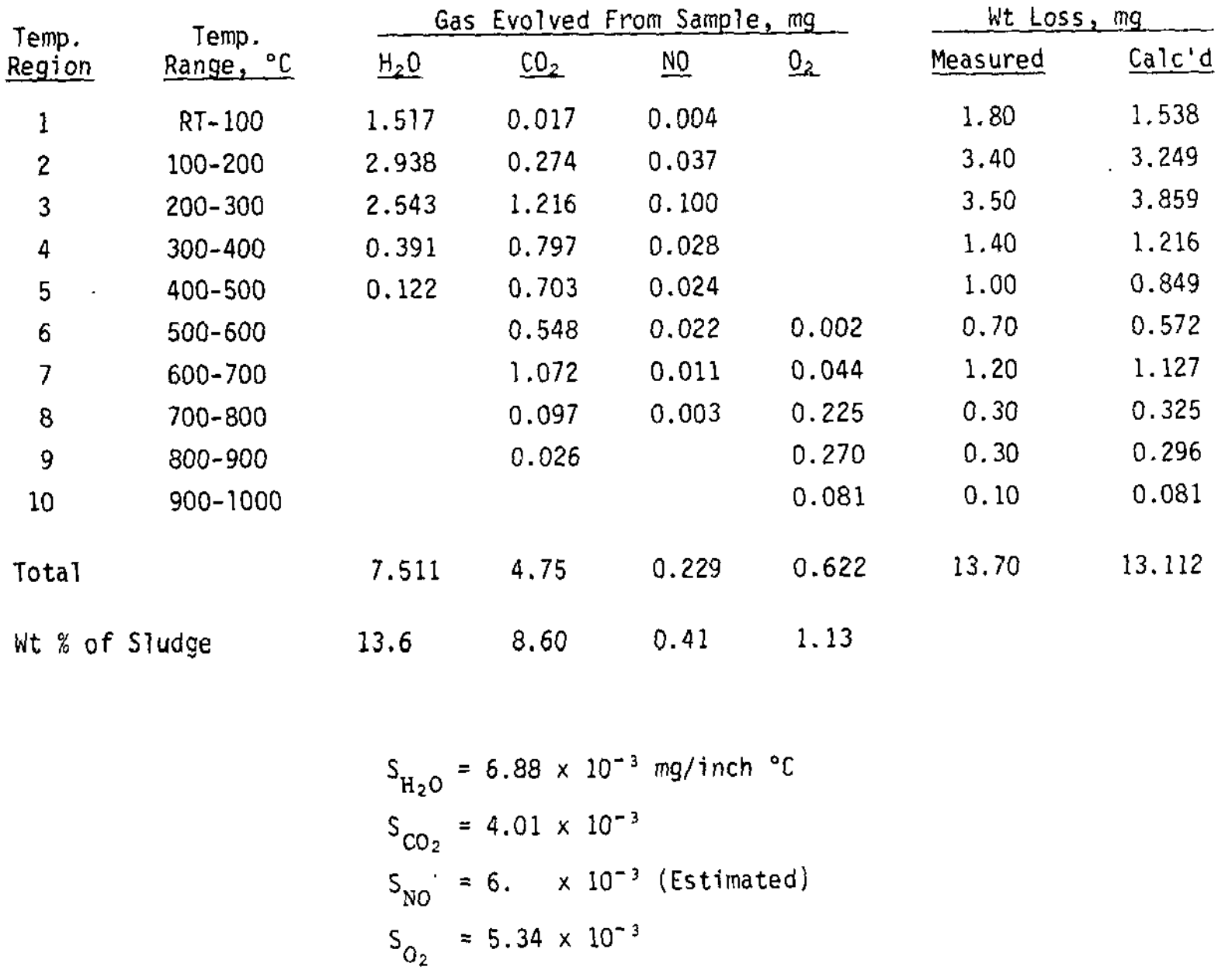


The evolved gas curves for the sludge analysis are similar to those for the calcine analysis, but significant differences are apparent. The evolved gas curve for water in sludge shows a maximum evolution rate for loosely bound water at $100^{\circ} \mathrm{C}$. However, a second peak not present in the calcine analysis occurs at $220^{\circ} \mathrm{C}$. The peak at $220^{\circ} \mathrm{C}$ is rather narrow and is superimposed on the slowly decreasing high temperature side of the $100^{\circ} \mathrm{C}$ peak. The peak at $100^{\circ} \mathrm{C}$ is attributed to loosely bound water and to water trapped by the hydrous oxide during precipitation. The peak at $220^{\circ} \mathrm{C}$ is attributed to water of hydration. Since the evolved gas curve for carbon dioxide at mass 44 also shows a narrow peak at exactly $220^{\circ} \mathrm{C}$, the hydrated species is presumed to be a carbonate or bicarbonate compound.

In addition to the gas evolved at $220^{\circ} \mathrm{C}$, the evolved gas curve for mass 44 shows a slowly decreasing and rather erratic evolution of gas from about $250^{\circ} \mathrm{C}$ to $550^{\circ} \mathrm{C}$. The gas evolved in this temperature region is presumed to be carbon dioxide from the decomposition of carbonate and/or bicarbonate species existing in various bonding environments. As before, the unlikely possibility exists that this portion of the evolved gas curve is due partly to nitrous oxide from nitrate decomposition. Between $550^{\circ} \mathrm{C}$ and $650^{\circ} \mathrm{C}$, rapid gas evolution occurs. This peak is analogous to the peak observed for calcine at $550^{\circ} \mathrm{C}$, but for sludge, the maximum evolution rate occurs at approximately $630^{\circ} \mathrm{C}$. This peak is attributed to carbon dioxide from carbonate decomposition.

The evolved gas curve for nitric oxide at mass 30 shows a small but narrow peak at about $240^{\circ} \mathrm{C}$. Although no corresponding peak was observed at this temperature for oxygen evolution, the peak is attributed to nitric oxide from nitrate decomposition.

The evolved gas curve for oxygen at mass 32 shows one broad peak at approximately $820^{\circ} \mathrm{C}$. This peak is attributed to the conversion of $\mathrm{Fe}_{2} \mathrm{O}_{3}$ to $\mathrm{Fe}_{3} \mathrm{O}_{4}$ and perhaps of $\mathrm{MnO}_{2}$ to $\mathrm{Mn}_{3} \mathrm{O}_{4}$ as previously discussed for the calcine analysis. By thermal conversion of $\mathrm{Fe}_{2} \mathrm{O}_{3}$ to $\mathrm{Fe}_{3} \mathrm{O}_{4}$ according to Equation 3, one atom of oxygen is evolved for every six atoms of iron converted to $\mathrm{Fe}_{3} \mathrm{O}_{4}$.

$$
3 \mathrm{Fe}_{2} \mathrm{O}_{3} \rightarrow 2 \mathrm{Fe}_{3} \mathrm{O}_{4}+1 / 2 \mathrm{O}_{2}
$$

For comparison, the oxygen to iron ratio was calculated for the sludge analysis from the experimental data of Table 11, the calcine composition of Table I, and the TGA initial and final weights by assuming that the elemental compositions for sludge and calcine are identical after heating to $1000^{\circ} \mathrm{C}$. The experimentally determined oxygen to iron ratio of 0.19 compares well with the theoretical ratio of 0.17 . These data support the conclusion that $\mathrm{Fe}_{2} \mathrm{O}_{3}$ and perhaps $\mathrm{MnO}_{2}$ are converted in the $700^{\circ}$ to $900^{\circ} \mathrm{C}$ temperature range to forms containing relatively less oxygen. 


\section{Differential Thermal Analysis of Calcine}

Differential thermal analysis (DTA) was run in an air atmosphere on a sample of calcine. The heating rate was $20^{\circ} \mathrm{C} / \mathrm{min}$, and $\mathrm{Al}_{2} \mathrm{O}_{3}$ was used as a reference. The DTA thermogram is shown in Figure 20.

The thermogram is interpreted as follows:

Temperature

Region, ${ }^{\circ} \mathrm{C}$

20-90

$90-400$

$400-650$

$>650$
Reaction Type

Endothermic

Endothermic

Exothermic

Small exothermic reaction at $770^{\circ}$
Comments

Loss of loosely adsorbed water

Loss of more tightly bound water

Decomposition primarily of carbonate species

Additional unspecified decomposition

Mössbauer Spectral Analyses

The Mössbauer spectrum of calcine at room temperature in zero applied magnetic field is shown in Figure 21. The Mössbauer spectrum of sludge at room temperature appears identical to that for calcine. The spectrum consists solely of a doublet centered at zero velocity and characteristic of the ferric ion. No ferrous iron is indicated by the spectrum. The simple paramagnetic spectrum and the absence of the typical six-peak magnetic spectrum effectively eliminate metallic iron, $\mathrm{Fe}_{2} \mathrm{O}_{3}$, and $\mathrm{Fe}_{3} \mathrm{O}_{4}$ as probable constituents of calcine and sludge. The alpha, beta, and delta forms of $\mathrm{FeOOH}$ are also unlikely components of calcine and sludge because these forms also show the six-peak hyperfine splitting at room temperature. Gamma $\mathrm{FeOOH}$ and fertic hydroxide gels give paramagnetic doublets down to at least $77^{\circ} \mathrm{K}$ and are likely constituents of calcine and sludge. Reference 3 is an excellent review of Mössbauer spectroscopy of ferric oxides and hydroxides with over 100 literature references.

\section{CONCLUSIONS}

Calcine is a rust-colored powder of approximately sperical particles with a mean diameter of $15 \mu \mathrm{m}$ and a particle size range of $3 \mathrm{\mu m}$ to at least $30 \mathrm{\mu m}$. The particles are primarily amorphous. They consist of hydrous oxides which trap water during sludge 


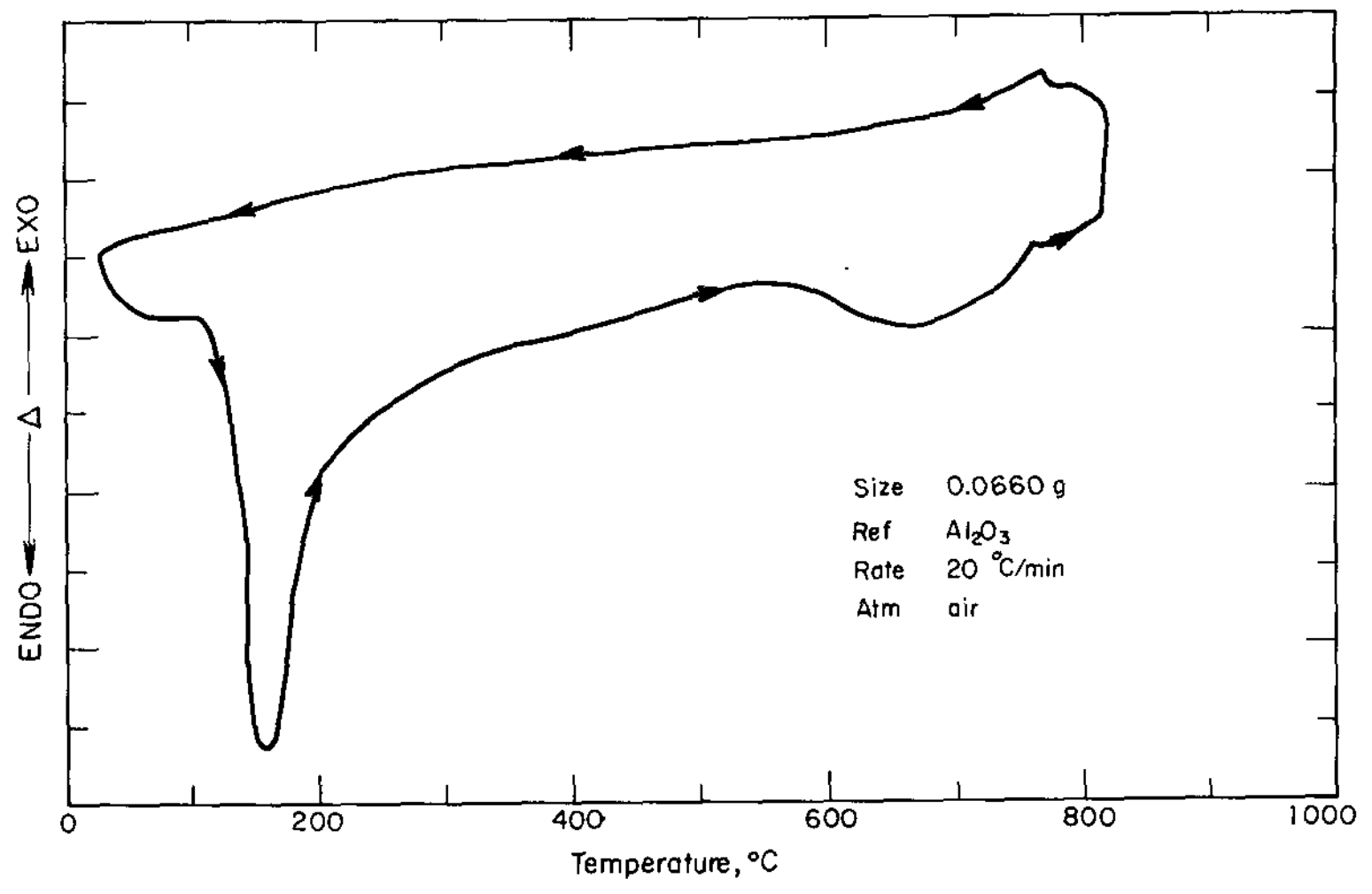

FIGURE 20. Differential Thermal Analysis of Calcine 


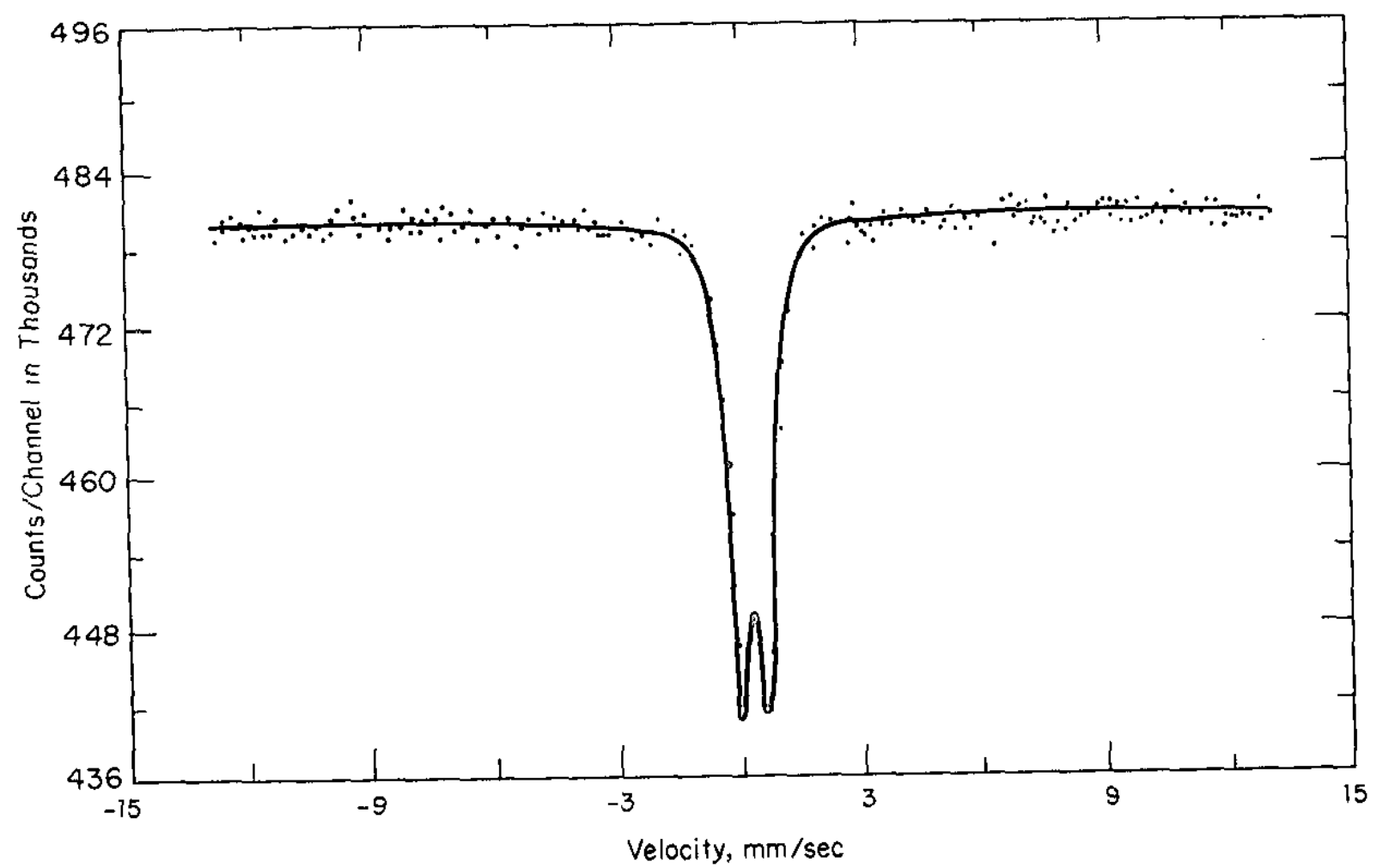

FIGURE 21. Möввbauer Spectrum of Calcine at Room Temperature 
precipitation but have no definite stoichiometric combination with water. A significant quantity of water $(6.1 \%)$ is present in the calcine.

Evolved gas analyses show that calcine is completely dehydrated by heating to $400^{\circ} \mathrm{C}$. Carbon dioxide is evolved from calcine between $100^{\circ}$ and $700^{\circ} \mathrm{C}$ with maximum evolution at $500^{\circ} \mathrm{C}$. Nitrate decomposition occurs between $200^{\circ}$ and $700^{\circ} \mathrm{C}$, and in a helium atmosphere, oxygen is evolved between $400^{\circ}$ and $1000^{\circ} \mathrm{C}$.

Iron, manganese, nickel, and calcium exist in the calcine in forms which are very insoluble in water. Approximately $60 \%$ of the aluminum, $73 \%$ of the sulfate, $88 \%$ of the nitrate, and $94 \%$ of the sodium (and presumably most of the carbonate) exist in watersoluble forms. The water-insoluble species are distributed quite uniformly over each particle, and compositional variations from particle to particle, although present, are relatively small. Iron exists entirely in the ferric state.

During calcination, sodium concentrates at the surface of the particles. Although the data are conclusive only for sodium, the other soluble ions presumably also tend to concentrate at the surface. The partial solubility of the aluminum and the high solubility of sodium suggest that sodium may be present on the particle surfaces as sodium aluminate and/or sodium hydroxide. These phases would account for the hygroscopic nature of the calcine.

A crystalline phase was detected in the calcine at very low concentration. This phase was identified by $x$-ray diffraction analysis as a spinel-type oxide similar to $\mathrm{NiFe}_{2} \mathrm{O}_{4}$ with a cubic structure and lattice constant of 8.33A. Detection of spinels in the calcine is particularly significant to the studies of calcine reactions in glass; spinels were previously believed to form only at high temperature during fusion of the calcine with glass frit. 


\section{REFERENCES}

1. Fina1 Environmental Impact Statement, Waste Management Operations, Savannah River Plant, Aiken, South Carolina. pp. 11-77, USERDA Report ERDA-1537, Washington, DC (1976).

2. Therald Moeller. Inorganic Chemistry. p. 501, John Wiley and Sons, New York (1952).

3. L. H. Bowen, "Mössbauer Spectroscopy of Ferric Oxides and Hydroxides." Mössbauer Effect Reference and Data Journal 2 , 76 (March 1, 1979). 


\section{APPENDICES}




\section{Preparation of Synthetic Calciner Feed Slurry}

The calciner feed slurry was chemically formulated to simulate an average waste composition by using the following procedure: A solution of iron, aluminum, nickel, and calcium nitrates was combined with a solution of $\mathrm{NaNO}_{3}, \mathrm{Na}_{2} \mathrm{SO}_{4}$, and $\mathrm{Na}_{2} \mathrm{CO}_{3}$ and a solution of $\mathrm{Mn}\left(\mathrm{NO}_{3}\right)_{2}$ containing a small quantity of $\mathrm{KMnO}_{4}$. Sodium hydroxide solution was slowly added to $\mathrm{pH} 9.5$ to precipitate the synthetic waste sludge. After precipitation, sodium nitrite solution was added to the waste slurry, and the slurry was slowly cooled to room temperature and centrifuged to recover the sludge. The sludge was washed with water adjusted to $\mathrm{pH} 9.5$ with $\mathrm{NaOH}$. After decanting the wash solution, calculated amounts of $\mathrm{pH} 9.5$ water and $\mathrm{Na}_{2} \mathrm{CO}_{3}$ were added to give the calciner feed slurry. 
APPENDIX 2

Experimental Data for Mass Spectrometric Analysis of Calcine and Sludge 
MASS SPECTROMETRIC DATA FOR CALCINE ANALYSIS

\begin{tabular}{|c|c|c|c|c|c|c|}
\hline \multirow{2}{*}{$\begin{array}{c}\text { Mass } \\
\text { Spectrum } \\
\text { Number } \\
\end{array}$} & \multirow{2}{*}{$\begin{array}{c}\text { TGA } \\
\begin{array}{c}\text { Temperature } \\
{ }^{\circ} \mathrm{C}\end{array} \\
\end{array}$} & \multicolumn{5}{|c|}{ Peak Heights, Inches } \\
\hline & & $\begin{array}{l}\text { Mass } \\
18 \\
\end{array}$ & $\begin{array}{c}\text { Mass } \\
28 \\
\end{array}$ & $\begin{array}{c}\text { Mass } \\
30 \\
\end{array}$ & $\begin{array}{c}\text { Mass } \\
32 \\
\end{array}$ & $\begin{array}{c}\text { Mass } \\
44 \\
\end{array}$ \\
\hline 2 & 27.5 & 3.87 & & & & \\
\hline 3 & 32.0 & 3.81 & 1.70 & 0.00 & 0.54 & 0.18 \\
\hline 4 & 36.5 & 4.02 & & & & \\
\hline 5 & 41.0 & 4.23 & 1.75 & 0.07 & 0.50 & 0.15 \\
\hline 6 & 45.5 & 4.74 & & & & \\
\hline 7 & 50.0 & 5.61 & 1.87 & 0.05 & 0.47 & 0.16 \\
\hline 8 & 56.7 & 6.39 & . & & & \\
\hline 9 & 63.3 & 7.02 & 1.84 & 0.06 & 0.50 & 0.14 \\
\hline 10 & 70.0 & 6.99 & & & & \\
\hline 11 & 76.7 & 7.32 & 1.88 & 0.08 & 0.51 & 0.10 \\
\hline 12 & 83.3 & 6.78 & & & & \\
\hline 13 & 90.0 & 6.75 & 1.95 & 0.10 & 0.54 & 0.16 \\
\hline 14 & 96.7 & 5.88 & & & & \\
\hline 15 & 103. & 6.15 & 1.90 & 0.05 & 0.50 & 0.17 \\
\hline 16 & 110. & 6.24 & & & & \\
\hline 17 & 117 . & 6.06 & 1.80 & 0.06 & 0.54 & 0.18 \\
\hline 18 & 123. & 5.61 & & & & \\
\hline 19 & 130. & 5.88 & 1.78 & 0.07 & 0.54 & 0.18 \\
\hline 20 & 137. & 5.67 & & & & \\
\hline 21 & 143. & 5.67 & 1.87 & 0.00 & 0.57 & 0.15 \\
\hline 22 & 150. & 5.70 & & & & \\
\hline 23 & 156. & 5.37 & 1.92 & 0.11 & 0.60 & 0.17 \\
\hline 24 & 161. & 5.49 & & & & \\
\hline 25 & 167. & 5.58 & 1.85 & 0.07 & 0.55 & 0.23 \\
\hline 26 & 172. & 4.71 & & & & \\
\hline 27 & 178 & 5.31 & 1.80 & 0.08 & 0.57 & 0.24 \\
\hline 29 & 189. & 5.13 & 1.82 & 0.06 & 0.55 & 0.34 \\
\hline 31 & 200. & 5.10 & 1.89 & 0.05 & 0.53 & 0.37 \\
\hline 33 & 211. & 5.40 & 1.89 & 0.07 & 0.60 & 0.41 \\
\hline 35 & 222. & 4.95 & 1.86 & 0.10 & 0.60 & 0.43 \\
\hline 37 & 233. & 5.40 & 2.05 & 0.11 & 0.57 & 0.50 \\
\hline
\end{tabular}


(Cont'd)

\begin{tabular}{|c|c|c|c|c|c|c|}
\hline \multirow[b]{2}{*}{$\begin{array}{c}\text { Mass } \\
\text { Spectrum } \\
\text { Number } \\
\end{array}$} & \multirow{2}{*}{$\begin{array}{c}\text { TGA } \\
\text { Temperature } \\
{ }^{\circ} \mathrm{C} \\
\end{array}$} & \multicolumn{5}{|c|}{ Peak Heights, Inches } \\
\hline & & $\begin{array}{c}\text { Mass } \\
18 \\
\end{array}$ & $\begin{array}{c}\text { Mass } \\
28 \\
\end{array}$ & $\begin{array}{c}\text { Mass } \\
30 \\
\end{array}$ & $\begin{array}{l}\text { Mass } \\
32 \\
\end{array}$ & $\begin{array}{c}\text { Mass } \\
44 \\
\end{array}$ \\
\hline 39 & 244. & 4.68 & 1.82 & 0.08 & 0.58 & 0.58 \\
\hline 41 & 256. & 5.07 & 1.91 & 0.10 & 0.62 & 0.64 \\
\hline 43 & 267. & 4.71 & 1.90 & 0.11 & 0.60 & 0.67 \\
\hline 45 & 278 & 4.86 & 1.87 & 0.12 & 0.56 & 0.74 \\
\hline 47 & 289. & 4.74 & 1.96 & 0.13 & 0.56 & 0.73 \\
\hline 49 & 300. & 4.59 & 1.83 & 0.10 & 0.56 & 0.79 \\
\hline 51 & 310. & 4.89 & 2.12 & 0.14 & 0.59 & 0.77 \\
\hline 53 & 320. & 4.65 & 2.07 & 0.14 & 0.55 & 0.80 \\
\hline 55 & 330. & 4.89 & 2.09 & 0.21 & 0.53 & 0.83 \\
\hline 57 & 340. & 4.56 & 2.02 & 0.25 & 0.56 & 0.85 \\
\hline 59 & 350. & 4.71 & 2.00 & 0.15 & 0.56 & 0.92 \\
\hline 61 & 360. & 4.65 & 2.08 & 0.18 & 0.59 & 0.93 \\
\hline 63 & 370. & 4.17 & 1.94 & 0.15 & 0.54 & 0.84 \\
\hline 65 & 380. & 4.74 & 2.10 & 0.18 & 0.54 & 0.89 \\
\hline 67 & 390. & 4.62 & 2.02 & 0.18 & 0.56 & 0.86 \\
\hline 69 & 400 & 4.92 & 2.00 & 0.14 & 0.60 & 0.99 \\
\hline 71 & 410. & 4.86 & 2.07 & 0.19 & 0.68 & 0.96 \\
\hline 73 & 420. & 4.59 & 2.08 & 0.16 & 0.64 & 1.07 \\
\hline 75 & 430 & 4.68 & 1.97 & 0.17 & 0.65 & 1.07 \\
\hline 77 & 440. & 4.80 & 2.20 & 0.20 & 0.75 & 1.15 \\
\hline 79 & 450. & 4.92 & 2.11 & 0.24 & 0.69 & 1.24 \\
\hline 81 & 460. & 5.16 & 2.30 & 0.29 & 0.82 & 1.28 \\
\hline 83 & 470. & 4.65 & 2.09 & 0.28 & 0.78 & 1.26 \\
\hline 85 & 480. & 4.86 & 2.29 & 0.38 & 0.80 & 1.30 \\
\hline 87 & 490. & 4.59 & 2.07 & 0.31 & 0.74 & 1.44 \\
\hline 89 & 500. & 4.41 & 2.09 & 0.20 & 0.80 & 1.49 \\
\hline 91 & 510. & 4.32 & 2.13 & 0.25 & 0.74 & 1.60 \\
\hline 93 & 519. & 4.80 & 2.35 & 0.27 & 0.73 & 1.87 \\
\hline 95 & 529. & 4.83 & 2.34 & 0.28 & 0.79 & 2.36 \\
\hline 97 & 538. & 4.92 & 2.38 & 0.31 & 0.72 & 3.00 \\
\hline 99 & 548. & 4.56 & 2.52 & 0.37 & 0.75 & 3.50 \\
\hline 100 & 552. & & & 0.33 & & 3.82 \\
\hline 101 & 557. & 4.95 & 2.60 & 0.30 & 0.72 & 3.75 \\
\hline 102 & 562. & & & 0.26 & & 3.68 \\
\hline 103 & 567. & 4.80 & 2.41 & 0.30 & 0.70 & 2.93 \\
\hline
\end{tabular}


(Cont'd)

\begin{tabular}{|c|c|c|c|c|c|c|}
\hline \multirow[b]{2}{*}{$\begin{array}{l}\text { Mass } \\
\text { Spectrum } \\
\text { Number }\end{array}$} & \multirow{2}{*}{ 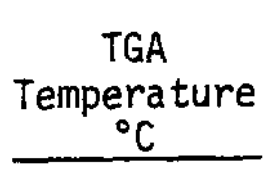 } & \multicolumn{5}{|c|}{ Peak Heights, Inches } \\
\hline & & $\begin{array}{c}\text { Mass } \\
18 \\
\end{array}$ & $\begin{array}{c}\text { Mass } \\
28 \\
\end{array}$ & $\begin{array}{c}\text { Mass } \\
30 \\
\end{array}$ & $\begin{array}{l}\text { Mass } \\
32 \\
\end{array}$ & $\begin{array}{c}\text { Mass } \\
44 \\
\end{array}$ \\
\hline 104 & 571. & & & 0.22 & & 2.63 \\
\hline 105 & 576. & 4.47 & 2.33 & 0.22 & 0.71 & 2.55 \\
\hline 106 & 581. & & & 0.19 & & 2.52 \\
\hline 107 & 586. & 5.10 & 2.40 & 0.16 & 0.70 & 2.79 \\
\hline 108 & 590. & & & 0.14 & & 2.55 \\
\hline 109 & 595. & 4.68 & 2.21 & 0.10 & 0.73 & 2.23 \\
\hline 110 & 600. & & & 0.09 & & 1.72 \\
\hline 111 & 605 & 4.86 & 2.16 & 0.12 & 0.71 & 1.05 \\
\hline 112 & 610. & & & & & 0.80 \\
\hline 113 & 615. & 4.86 & 2.15 & 0.12 & 0.71 & 0.64 \\
\hline 114 & 620. & & & 0.11 & & 0.61 \\
\hline 115 & 625. & 4.92 & 2.03 & 0.11 & 0.77 & 0.50 \\
\hline 116 & 630 & & & & & 0.46 \\
\hline 117 & 635. & 4.59 & 2.24 & 0.11 & 0.76 & 0.33 \\
\hline 119 & 645. & 5.22 & 2.11 & 0.06 & 0.80 & 0.28 \\
\hline 121 & 655. & 5.10 & 2.10 & 0.03 & 0.75 & 0.23 \\
\hline 123 & 665. & 5.07 & 2.14 & 0.12 & 0.81 & 0.14 \\
\hline 125 & 675. & 5.07 & 2.00 & 0.06 & 0.80 & 0.22 \\
\hline 127 & 685. & 5.34 & 2.23 & 0.05 & 0.78 & 0.17 \\
\hline 129 & 695. & 4.86 & 2.03 & 0.04 & 0.86 & 0.16 \\
\hline 131 & 705. & 5.16 & 2.17 & 0.10 & 0.90 & 0.15 \\
\hline 133 & 716. & 5.10 & 2.10 & 0.08 & 0.88 & 0.14 \\
\hline 135 & 726. & 5.07 & 2.10 & 0.09 & 0.96 & 0.11 \\
\hline 137 & 737. & 5.22 & 2.24 & 0.11 & 0.98 & 0.12 \\
\hline 139 & 747. & 5.31 & 2.04 & 0.06 & 0.94 & 0.18 \\
\hline 141 & 758. & 5.22 & 2.00 & 0.02 & 0.94 & 0.14 \\
\hline 143 & 768. & 5.76 & 2.14 & 0.03 & 0.90 & 0.14 \\
\hline 145 & 779. & 5.16 & 2.06 & 0.14 & 0.93 & 0.12 \\
\hline 147 & 790. & 5.19 & 2.07 & 0.06 & 0.95 & 0.15 \\
\hline 149 & 800. & 5.25 & 2.06 & 0.07 & 0.95 & 0.10 \\
\hline 151 & 810. & 5.70 & 2.26 & 0.11 & 0.94 & 0.11 \\
\hline 153 & 821. & 5.46 & 2.05 & 0.05 & 0.84 & 0.14 \\
\hline 155 & 832: & 5.28 & 1.96 & 0.03 & 0.83 & 0.13 \\
\hline 157 & 842. & 5.43 & 2.02 & 0.06 & 0.85 & 0.15 \\
\hline 159 & 853. & 5.46 & 2.05 & 0.04 & 0.81 & 0.15 \\
\hline
\end{tabular}


(Cont'd)

\begin{tabular}{|c|c|c|c|c|c|c|}
\hline \multirow{2}{*}{$\begin{array}{l}\text { Mass } \\
\text { Spectrum } \\
\text { Number } \\
\end{array}$} & \multirow{2}{*}{$\begin{array}{c}\text { TGA } \\
\text { Temperature } \\
{ }^{\circ} \mathrm{C} \\
\end{array}$} & \multicolumn{5}{|c|}{ Peak Heights, Inches } \\
\hline & & $\begin{array}{c}\text { Mass } \\
18 \\
\end{array}$ & $\begin{array}{l}\text { Mass } \\
.28 \\
\end{array}$ & $\begin{array}{c}\text { Mass } \\
30 \\
\end{array}$ & $\begin{array}{c}\text { Mass } \\
32 \\
\end{array}$ & $\begin{array}{c}\text { Mass } \\
44 \\
\end{array}$ \\
\hline 161 & 863. & 5.61 & 2.13 & 0.06 & 0.77 & 0.16 \\
\hline 163 & 874. & 5.76 & 2.15 & 0.05 & 0.80 & 0.15 \\
\hline 165 & 884. & 5.67 & 2.13 & 0.07 & 0.87 & 0.10 \\
\hline 167 & 895. & 5.46 & 2.00 & 0.06 & 0.72 & 0.16 \\
\hline 169 & 905. & 5.34 & 1.97 & 0.14 & 0.78 & 0.14 \\
\hline 171 & 915. & 5.79 & 2.12 & 0.06 & 0.74 & 0.16 \\
\hline 173 & 925. & 6.15 & 2.16 & 0.06 & 0.72 & 0.14 \\
\hline 175 & 935. & 5.61 & 1.98 & 0.09 & 0.72 & 0.14 \\
\hline 177 & 945. & 6.33 & 2.21 & 0.07 & 0.65 & 0.16 \\
\hline 179 & 955. & 5.94 & 1.96 & 0.07 & 0.73 & 0.13 \\
\hline 181 & 965. & 6.06 & 2.02 & 0.06 & 0.68 & 0.20 \\
\hline 183 & 975. & 5.97 & 2.00 & 0.10 & 0.68 & 0.12 \\
\hline 185 & 985. & 6.27 & 2.01 & 0.07 & 0.68 & 0.16 \\
\hline 187 & 995. & 6.21 & 2.00 & 0.10 & 0.71 & 0.16 \\
\hline $189^{\circ}$ & 1005. & 6.15 & 2.00 & 0.08 & 0.60 & 0.13 \\
\hline
\end{tabular}




\section{MASS SPECTROMETRIC DATA FOR SLUDGE ANALYSIS}

\begin{tabular}{|c|c|c|c|c|c|c|}
\hline \multirow{2}{*}{$\begin{array}{l}\text { Mass } \\
\text { Spectrum } \\
\text { Number } \\
\end{array}$} & \multirow{2}{*}{$\begin{array}{c}\text { TGA } \\
\text { Temperature } \\
{ }^{\circ} \mathrm{C} \\
\end{array}$} & \multicolumn{5}{|c|}{ Peak Hejghts, Inches } \\
\hline & & $\begin{array}{c}\text { Mass } \\
18 \\
\end{array}$ & $\begin{array}{c}\text { Mass } \\
28 \\
\end{array}$ & $\begin{array}{l}\text { Mass } \\
30 \\
\end{array}$ & $\begin{array}{c}\text { Mass } \\
32 \\
\end{array}$ & $\begin{array}{c}\text { Mass } \\
44 \\
\end{array}$ \\
\hline 1 & 23.0 & 4.35 & 1.60 & 0.10 & 0.47 & 0.12 \\
\hline 4 & 38.4 & 4.05 & 1.50 & 0.10 & 0.44 & 0.10 \\
\hline 8 & 58.9 & 5.55 & 1.48 & 0.10 & 0.40 & 0.14 \\
\hline 12 & 79.5 & 9.15 & 1.60 & 0.11 & 0.40 & 0.22 \\
\hline 16 & 100. & 9.96 & 1.70 & 0.08 & 0.44 & 0.28 \\
\hline 20 & 124. & 9.48 & 1.70 & 0.12 & 0.48 & 0.37 \\
\hline 24 & 147. & 7.95 & 1.68 & 0.13 & 0.49 & 0.57 \\
\hline 26 & 159. & 7.74 & 1.70 & 0.08 & 0.41 & 0.79 \\
\hline 28 & 171. & 7.86 & 1.72 & 0.12 & 0.39 & 1.04 \\
\hline 29 & 176. & 7.38 & 1.65 & 0.18 & 0.40 & 1.29 \\
\hline 30 & 182. & 7.50 & 1.81 & 0.12 & 0.38 & 1.40 \\
\hline 31 & 188. & 7.50 & 1.78 & 0.12 & 0.42 & 1.69 \\
\hline 32 & 194. & 7.35 & 1.76 & 0.20 & 0.48 & 1.90 \\
\hline 33 & 200. & 7.44 & 1.74 & 0.17 & 0.39 & 2.19 \\
\hline 34 & 205. & 8.40 & 1.82 & 0.20 & 0.40 & 2.63 \\
\hline 35 & 210. & 9.72 & 2.11 & 0.19 & 0.50 & 3.28 \\
\hline 36 & 216. & 10.6 & 2.02 & 0.19 & 0.41 & 4.10 \\
\hline 37 & 221. & 12.3 & 2.17 & 0.21 & 0.41 & 4.10 \\
\hline 38 & 226. & 11.0 & 1.98 & 0.21 & 0.40 & 4.10 \\
\hline 39 & 232. & & & 0.25 & & \\
\hline 40 & 237. & 9.42 & 2.00 & 0.34 & 0.35 & 3.47 \\
\hline 41 & 242. & & & 0.38 & & \\
\hline 42 & 247. & 7.44 & 1.84 & 0.35 & 0.42 & 3.08 \\
\hline 43 & 253. & & & 0.32 & & \\
\hline 44 & 258. & 7.47 & 1.86 & 0.20 & 0.42 & 3.10 \\
\hline 45 & 263. & & & 0.15 & & \\
\hline 46 & 268. & 6.60 & 1.85 & 0.19 & 0.46 & 2.96 \\
\hline 47 & 274 . & & & 0.19 & & \\
\hline 48 & 279. & 6.09 & 1.82 & 0.18 & 0.42 & 2.72 \\
\hline 49 & 284. & & & 0.12 & & 2.59 \\
\hline 50 & 290. & 5.94 & 1.81 & 0.13 & 0.39 & 2.52 \\
\hline
\end{tabular}




\begin{tabular}{|c|c|c|c|c|c|c|}
\hline \multirow{2}{*}{$\begin{array}{c}\text { Mass } \\
\text { Spectrum } \\
\text { Number } \\
\end{array}$} & \multirow{2}{*}{$\begin{array}{c}\text { TGA } \\
\text { Temperature } \\
\end{array}$} & \multicolumn{5}{|c|}{ Peak Heights, Inches } \\
\hline & & $\begin{array}{c}\text { Mass } \\
18 \\
\end{array}$ & $\begin{array}{l}\text { Mass } \\
28 \\
\end{array}$ & $\begin{array}{c}\text { Mass } \\
30 \\
\end{array}$ & $\begin{array}{c}\text { Mass } \\
32 \\
\end{array}$ & $\begin{array}{c}\text { Mass } \\
44 \\
\end{array}$ \\
\hline 51 & 295. & & & 0.15 & & 2.40 \\
\hline 52 & 300. & 5.67 & 1.87 & 0.14 & 0.42 & 2.28 \\
\hline 54 & 310. & & & 0.12 & & 2.24 \\
\hline 56 & 321. & 5.25 & 1.81 & 0.14 & 0.36 & 2.23 \\
\hline 58 & 332. & & & 0.09 & & 2.21 \\
\hline 60 & 342. & 5.31 & 1.82 & 0.08 & 0.40 & 2.28 \\
\hline 61 & 347. & & & & & 2.23 \\
\hline 62 & 353. & & & 0.08 & & 2.12 \\
\hline 64 & 363. & 4.74 & 1.71 & 0.07 & 0.39 & 2.05 \\
\hline 66 & 374. & & & 0.09 & & 2.03 \\
\hline 67 & 379. & & & & & 1.83 \\
\hline 68 & 384. & 4.80 & 1.79 & 0.12 & 0.43 & 1.87 \\
\hline 70 & 395. & & & 0.09 & & 2.06 \\
\hline 72 & 405. & 4.98 & 1.87 & 0.11 & 0.43 & 2.01 \\
\hline 74 & 414. & & & 0.11 & & \\
\hline 76 & 424. & 4.71 & 1.69 & 0.09 & 0.45 & 1.98 \\
\hline 78 & 433. & & & 0.05 & & \\
\hline 80 & 443. & 5.10 & 2.03 & 0.12 & 0.41 & 1.95 \\
\hline 84 & 462. & 4.80 & 1.84 & 0.09 & 0.41 & 1.85 \\
\hline 88 & 481. & 4.80 & 1.82 & 0.10 & 0.43 & 1.85 \\
\hline 92 & 500. & 4.77 & 1.77 & 0.12 & 0.41 & 1.57 \\
\hline 96 & 519. & 4.86 & 1.75 & & 0.39 & 1.59 \\
\hline 97 & 524. & 4.62 & 1.69 & & 0.39 & 1.48 \\
\hline 98 & 529. & 5.10 & 1.78 & & 0.42 & 1.37 \\
\hline 99 & 533. & & 1.92 & & 0.43 & 1.35 \\
\hline 100 & 538. & 4.56 & 1.60 & 0.11 & 0.43 & 1.24 \\
\hline 101 & 543. & & & & & 1.23 \\
\hline 102 & 548. & 4.56 & 1.69 & & 0.40 & 1.15 \\
\hline 103 & 552. & & & & & 1.16 \\
\hline 104 & 557. & 4.89 & 1.78 & 0.09 & 0.44 & 1.11 \\
\hline 105 & 562. & 5.01 & 1.75 & & 0.48 & 1.13 \\
\hline 106 & 567. & 4.95 & 1.71 & & 0.40 & 1.14 \\
\hline 107 & 571. & 4.62 & & & & 1.23 \\
\hline 108 & 576. & 4.80 & 1.87 & 0.11 & & 1.31 \\
\hline 109 & 581. & 4.86 & 1.85 & & 0.38 & 1.55 \\
\hline
\end{tabular}


(Cont'd)

\begin{tabular}{|c|c|c|c|c|c|c|}
\hline \multirow{2}{*}{$\begin{array}{l}\text { Máss } \\
\text { Spectrum } \\
\text { Number } \\
\end{array}$} & \multirow{2}{*}{$\begin{array}{c}\text { TGA } \\
\text { Temperature } \\
{ }^{\circ} \mathrm{C} \\
\end{array}$} & \multicolumn{5}{|c|}{ Peak Heights, Inches } \\
\hline & & $\begin{array}{c}\text { Mass } \\
18\end{array}$ & $\begin{array}{c}\text { Mass } \\
28 \\
\end{array}$ & $\begin{array}{c}\text { Mass } \\
30\end{array}$ & $\begin{array}{c}\text { Mass } \\
32\end{array}$ & $\begin{array}{c}\text { Mass } \\
44\end{array}$ \\
\hline 110 & 586. & 4.68 & 1.73 & & 0.43 & 1.81 \\
\hline 111 & 590. & & 2.00 & & & 2.63 \\
\hline 112 & 595. & 4.92 & 2.02 & 0.10 & 0.45 & 2.88 \\
\hline 113 & 600. & 4.77 & 2.00 & 0.12 & 0.48 & 3.41 \\
\hline 114 & 605. & 4.86 & 2.02 & & 0.46 & 4.24 \\
\hline 115 & 610. & 4.74 & 2.09 & & 0.43 & 4.83 \\
\hline 116 & 614. & 4.95 & 2.14 & 0.07 & 0.41 & 5.19 \\
\hline 117 & 619. & 4.80 & 2.14 & & 0.42 & 5.91 \\
\hline 118 & 624. & 4.71 & 2.26 & & 0.43 & 6.01 \\
\hline 119 & 629. & 4.74 & 2.22 & & 0.49 & 6.11 \\
\hline 120 & 633. & 4.83 & 2.23 & 0.08 & 0.47 & 5.72 \\
\hline 121 & 638. & & 2.07 & & 0.44 & 4.60 \\
\hline 122 & 643. & 4.80 & 1.86 & & 0.48 & 3.45 \\
\hline 123 & 648. & & & & & 2.36 \\
\hline 124 & 652. & 4.71 & 1.69 & 0.09 & 0.48 & 1.30 \\
\hline 125 & 657. & & & & & 0.82 \\
\hline 126 & 662. & 4.26 & 1.60 & 0.10 & 0.47 & 0.70 \\
\hline 130 & 681. & 4.83 & 1.64 & 0.10 & 0.55 & 0.58 \\
\hline 134 & 700. & 4.74 & 1.66 & 0.06 & 0.58 & 0.55 \\
\hline 136 & 710. & 5.07 & 1.71 & 0.10 & 0.70 & 0.55 \\
\hline 140 & 732 . & 5.01 & 1.78 & 0.08 & 0.85 & 0.51 \\
\hline 144 & 753. & 5.01 & 1.80 & 0.11 & 0.95 & 0.42 \\
\hline 148 & 774. & 5.40 & 1.66 & 0.06 & 0.85 & 0.44 \\
\hline 152 & 795. & 5.31 & 1.70 & 0.05 & 0.91 & 0.38 \\
\hline 156 & 816. & 5.13 & 1.72 & 0.10 & 1.00 & 0.38 \\
\hline 160 & 837. & 5.22 & 1.63 & 0.10 & 0.98 & 0.33 \\
\hline 164 & 858. & 5.28 & 1.70 & 0.12 & 1.03 & 0.28 \\
\hline 168 & 879. & 5.52 & 1.70 & 0.11 & 0.87 & 0.29 \\
\hline 172 & 900. & 5.10 & 1.58 & 0.06 & 0.62 & 0.30 \\
\hline 176 & 920. & 5.55 & 1.60 & 0.06 & 0.67 & 0.27 \\
\hline 180 & 940. & 5.34 & 1.62 & 0.10 & 0.57 & 0.28 \\
\hline 184 & 960. & 5.43 & 1.65 & 0.09 & 0.58 & 0.30 \\
\hline 188 & 980. & 5.13 & 1.62 & 0.08 & 0.48 & 0.32 \\
\hline 191 & 995. & 5.73 & 1.68 & 0.00 & 0.51 & 0.33 \\
\hline
\end{tabular}


APPENDIX 3 


\section{APPENDIX 3}

\section{Calculation of Evolved Gas Sensitivities}

Gases evolved during thermogravimetric analys is of calcine and of sludge were analyzed every 30 seconds by mass spectrometry. Evolved gas sensitivities were calculated for the four evolved gases by mathematicaliy fitting the mass spectrometric data to equations relating the evolved gas sensitivities to incremental weight losses. The sensitivity for each gas was assumed to be constant over the course of the experiment. Experimental data for these analyses and the calculated sensitivities are presented in the text of this report. The graphs of weight loss versus temperature and of mass spectrometric peak height versus temperature are particularly relevant to the following derivation of equations to calculate the evolved gas sensitivities.

From theoretical considerations, an evolved gas sensitivity $S_{x}$ should exist for each gas such that Equation 1 is valid over any specified temperature region within the analysis range.

$$
w_{x}=S_{x} A_{x}
$$

In Equation 1, $W_{x}$ denotes the weight of gas $x$ evolved and $A_{x}$ denotes the net area under the curve of mass spectrometric peak height versus temperature. To organize the experimental data into a form appropriate for calculating sensitivities for each evolved gas, the analysis temperature range of room temperature to $1000^{\circ} \mathrm{C}$ was divided into ten approximately equal regions. Since the mass spectrometric data showed that oniy $\mathrm{H}_{2} \mathrm{O}$, $\mathrm{CO}_{2}$, NO, and $\mathrm{O}_{2}$ were evolved during the analysis, the total calculated weight loss WLC for any region must be given by

$$
W L C=W_{\mathrm{H}_{2} \mathrm{O}}+W_{\mathrm{CO}_{2}}+W_{\mathrm{NO}}+W_{\mathrm{O}_{2}}
$$


Furthermore, within experimental uncertainty, WLC must equal the weight loss WLX determined experimentally during thermogravimetric anaiysis. The difference $D$ between the calculated weight loss and the experimentally determined weight loss is thus given for each region by

$D=S_{\mathrm{H}_{2} \mathrm{O}} A_{\mathrm{H}_{2} \mathrm{O}}+S_{\mathrm{CO}_{2}} A_{\mathrm{CO}_{2}}+S_{\mathrm{NO}} A_{\mathrm{NO}}+S_{\mathrm{O}_{2}} A_{\mathrm{O}_{2}}-$ WLX.

Since the analys is range was divided into ten temperature regions, ten equations and ten values for $D$ exist. The respective areas and experimentally determined weight losses for these equations are given in Table 6 for the calcine analysis. The respective sensitivities for $\mathrm{H}_{2} \mathrm{O}, \mathrm{CO}_{2}, \mathrm{NO}$, and $\mathrm{O}_{2}$ are identical in each of the ten equations. These sensitivities can be evaluated to best fit the overall data by minimizing the sum of the squares of the ten $D$ values.

The equations for $D^{2}$ and for the sum of the $D^{2}$ are as follows where the numerical subscript denotes the temperature region:

$$
\begin{aligned}
& O_{1}^{2}=\left(S_{\mathrm{H}_{2} \mathrm{O}} A_{\mathrm{H}_{2} \mathrm{O}_{1}}+S_{\mathrm{CO}_{2}} A_{\mathrm{CO}_{21}}+S_{\mathrm{NO}} A_{\mathrm{NO}_{1}}+S_{\mathrm{O}_{2}} A_{\mathrm{O}_{2}}-W\left(X_{1}\right)^{2}\right. \\
& D_{2}^{2}=\left(S_{\mathrm{H}_{2} \mathrm{O}} A_{\mathrm{H}_{2} \mathrm{O}_{2}}+S_{\mathrm{CO}_{2}} A_{\mathrm{CO}_{22}}+S_{\mathrm{NO}_{\mathrm{O}}} A_{\mathrm{NO}_{2}}+S_{\mathrm{O}_{2}} A_{\mathrm{O}_{2}}-W L X_{2}\right)^{2} \\
& \vdots \\
& D_{10}^{2}=\left(S_{\mathrm{H}_{2} \mathrm{O}} A_{\mathrm{H}_{2} \mathrm{O}_{10}}+S_{\mathrm{CO}_{2}} A_{\mathrm{CO}_{2}}+S_{\mathrm{NO}_{10}} A_{\mathrm{NO}_{10}}+S_{\mathrm{O}_{2}} A_{\mathrm{O}_{21}}-W L X_{10}\right)^{2} \\
& \Sigma D^{2}=D_{1}^{2}+D_{2}^{2}+D_{3}^{2} \cdot++D_{10}^{2}
\end{aligned}
$$

Since $E D^{2}$ has its minimum value when

$$
\frac{\partial \Sigma D^{2}}{\partial S_{\mathrm{H}_{2} \mathrm{O}}}=\frac{\partial \Sigma D^{2}}{\partial S_{\mathrm{CO}_{2}}}=\frac{\partial \Sigma D^{2}}{\partial S_{\mathrm{NO}}}=\frac{\partial \Sigma D^{2}}{\partial S_{\mathrm{O}_{2}}}=0
$$

we can calculate each partial derivative, set each partial derivative equal to zero, and simplify the resulting equations. To illustrate the calculation for the $\frac{\partial \Sigma D^{2}}{\partial \mathrm{S}_{\mathrm{H}_{2} \mathrm{O}}}$, we get 


$$
\begin{aligned}
& \frac{\partial \sum D^{2}}{\partial S_{\mathrm{H}_{2} \mathrm{O}}}=2\left(\mathrm{~S}_{\mathrm{H}_{2} \mathrm{O}} A_{\mathrm{H}_{2} \mathrm{O}_{1}}+S_{\mathrm{CO}_{2}} A_{\mathrm{CO}_{2_{1}}}+S_{\mathrm{NO}} A_{\mathrm{NO}_{1}}+S_{\mathrm{O}_{2}} A_{\mathrm{O}_{2}}-W L X_{1}\right) A_{\mathrm{H}_{2} \mathrm{O}_{1}} \\
& +2\left(\mathrm{~S}_{\mathrm{H}_{2} \mathrm{O}} \mathrm{A}_{\mathrm{H}_{2} \mathrm{O}}+\mathrm{S}_{\mathrm{CO}_{2}} \mathrm{~A}_{\mathrm{CO}_{2}}+\mathrm{S}_{\mathrm{NO}} \mathrm{ANO}_{2}+\mathrm{S}_{\mathrm{O}_{2}} \mathrm{~A}_{\mathrm{O}_{2}}-\underset{2}{W L X}\right) \mathrm{A}_{\mathrm{H}_{2} \mathrm{O}} \\
& +\dot{2}\left\langle\mathrm{~S}_{\mathrm{H}_{2} \mathrm{O}} A_{\mathrm{H}_{2} \mathrm{O}_{10}}+\mathrm{S}_{\mathrm{CO}_{2}} A_{\mathrm{CO}_{2} 10}+S_{\mathrm{NO}} A_{\mathrm{NO}_{10}}+S_{\mathrm{O}_{2}} A_{\mathrm{O}_{2}}=W L \mathrm{WL}_{10}\right\rangle A_{\mathrm{H}_{2} \mathrm{O}}=0
\end{aligned}
$$

This partial derivative simplifies to give Equation 2 below. Similar calculations for $\frac{\partial \Sigma D^{2}}{\partial S_{\mathrm{CO}_{2}}}, \frac{\partial E D^{2}}{\partial S_{\mathrm{NO}}}$, and $\frac{\partial E D^{2}}{\partial \mathrm{S}_{2}}$ give Equations 3,4 , and 5 respectively.

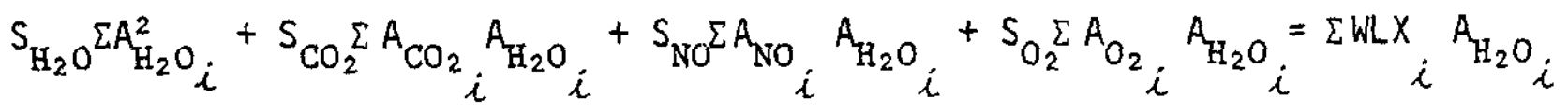

$$
\begin{aligned}
& \mathrm{S}_{\mathrm{H}_{2} \mathrm{O}} \sum \mathrm{A}_{\mathrm{H}_{2} \mathrm{O}} \mathrm{A}_{\mathrm{CO}_{2}}+\mathrm{S}_{\mathrm{CO}_{2}} \sum \mathrm{A}_{\mathrm{CO}_{2}}^{2}+\mathrm{S}_{\mathrm{NO}} \sum \mathrm{ANO}_{i} \mathrm{~A}_{\mathrm{CO}_{2}}+\mathrm{S}_{\mathrm{O}_{2}} \sum \mathrm{A}_{\mathrm{O}_{2}} A_{\mathrm{CO}_{2}}=\sum W L X{ }_{i} \mathrm{~A}_{\mathrm{CO}_{2}} \\
& S_{\mathrm{H}_{2} \mathrm{O}} \sum \mathrm{A}_{\mathrm{H}_{2} \mathrm{O}} \mathrm{A}_{\mathrm{NO}}+S_{\mathrm{CO}_{2}} \sum \mathrm{A}_{\mathrm{CO}_{2}} A_{\mathrm{NO}_{i}}+S_{\mathrm{NO}} \sum \mathrm{A}_{\mathrm{NO}}^{2}+S_{\mathrm{O}_{2}} \sum \mathrm{A}_{\mathrm{O}_{2}} \mathrm{ANO}_{i}=\sum \omega L X \mathrm{ANO}_{i}
\end{aligned}
$$

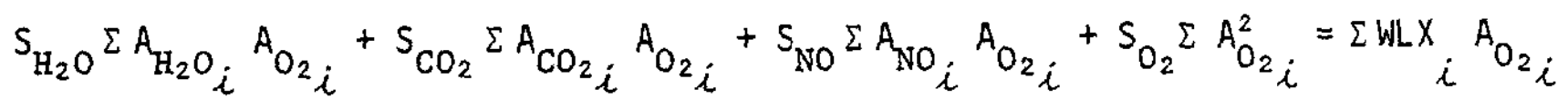

Equations 2 through 5 define the requirements for a least squares fit of the mass spectrometric-thermogravimetric analysis data to calculate evolved gas sensitivities for $\mathrm{H}_{2} \mathrm{O}, \mathrm{CO}_{2}, \mathrm{NO}$, AND $\mathrm{O}_{2}$. These simultaneous equations were used to calculate the sensitivities for Tabie 7 and for Table 10, Method 1.

For Methods 2 and 3 of Table 10, only three sensitivities were calculated; the sensitivity for nitric oxide was either completely disregarded or its value was assumed. Equations 6,7 , and 8 define the requirements for a least squares fit of the experimental data to calculate evolved gas sensitivities for $\mathrm{H}_{2} \mathrm{O}, \mathrm{CO}_{2}$, and $\mathrm{O}_{2}$. 
$\mathrm{S}_{\mathrm{H}_{2} \mathrm{O}} \sum \mathrm{A}_{\mathrm{H}_{2} \mathrm{O}}^{2}+\mathrm{S}_{\mathrm{CO}_{2}} \sum \mathrm{A}_{\mathrm{CO}_{2}} \mathrm{~A}_{\mathrm{H}_{2} \mathrm{O}}+\mathrm{S}_{\mathrm{O}_{2}} \sum \mathrm{A}_{\mathrm{O}_{2}} \mathrm{~A}_{\mathrm{H}_{2} \mathrm{O}}=\sum W L X \mathrm{~A}_{i} \mathrm{H}_{2} \mathrm{O}_{i}$

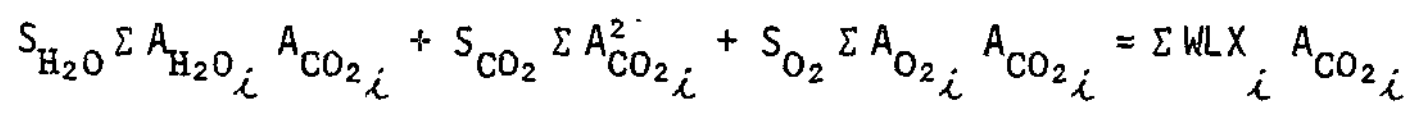

$\mathrm{S}_{\mathrm{H}_{2} \mathrm{O}} \sum \mathrm{A}_{\mathrm{H}_{2} \mathrm{O}} \mathrm{A}_{\mathrm{O}_{2}}+\mathrm{S}_{\mathrm{CO}_{2}} \sum \mathrm{A}_{\mathrm{CO}_{2}} \mathrm{~A}_{\mathrm{O}_{2}}+\mathrm{S}_{\mathrm{O}_{2}} \sum \mathrm{A}_{\mathrm{O}_{2}}^{2}=\sum W L \mathrm{WX}_{i} \mathrm{~A}_{\mathrm{O}_{2}}$

Standard Deviations of Evolved Gas Sensitivities

The reliability of the calculated sensitivities for the calcine analysis was estimated by the following empirical method: Relative standard deviations were estimated for each area measurement in each temperature region. Uncertainties in the weight loss measurements were assumed to be negligible. Computer-generated random normal deviates were used to randomly vary each experimentally determined area measurement within the predefined limits. After randomly varying each area measurement, the four sensitivities were calculated. Areas were varied and sensitivities were recalculated until 100 values had been generated for each evolved gas sensitivity. The standard deviation of the 100 values was then calculated. These standard deviations are reported in Table 7 for the calcine analysis. 